\title{
Title: Solid-state phase transformation and self-assembly of amorphous nanoparticles into higher-order mineral structures
}

Authors: Stanislas Von Euw ${ }^{1,7^{*}}$, Thierry Azaïs ${ }^{2}$, Viacheslav Manichev ${ }^{3,4}$, Guillaume Laurent $^{2}$, Gérard Pehau-Arnaudet ${ }^{5}$, Margarita Rivers ${ }^{4,6}$, Nagarajan Murali ${ }^{3}$, Daniel J. Kelly ${ }^{7}$, Paul G. Falkowski ${ }^{1,3 *}$

${ }^{1}$ Environmental Biophysics and Molecular Ecology Program, Department of Marine and Coastal Sciences, Rutgers University, 71 Dudley Road, New Brunswick, New Jersey, 08901, United States.

${ }^{2}$ Laboratoire de Chimie de la Matière Condensée de Paris, Sorbonne Université, CNRS, 4 place Jussieu, F-75005, Paris, France.

${ }^{3}$ Department of Chemistry and Chemical Biology, Rutgers University, 123 Bevier Road, Piscataway, New Jersey, 08854, United States.

${ }^{4}$ Institute of Advanced Materials, Devices, and Nanotechnology, Rutgers University, 607 Taylor Road, Piscataway, New Jersey, 08854, United States.

${ }^{5}$ UMR 3528 and UTech UBI, Institut Pasteur, 28 rue du Docteur Roux, F-75015 Paris, France.

${ }^{6}$ Department of Physics, Wellesley College, 106 Central Street, Wellesley, Massachusetts, 02481, United States.

${ }^{7}$ Trinity Centre for Bioengineering, Trinity Biomedical Sciences Institute, Trinity College Dublin, Dublin 2, D02 R590, Ireland.

*correspondence to: voneuws@tcd.ie; falko@marine.rutgers.edu 
Abstract:

Materials science has been informed by nonclassical pathways to crystallization based on biological processes to fabricate damage-tolerant composite materials. Various biomineralizing taxa, such as stony corals, deposit metastable, magnesium-rich, amorphous calcium carbonate nanoparticles that further assemble and transform into higher-order mineral structures. Here we examine a similar process in abiogenic conditions using synthetic, amorphous calcium magnesium carbonate nanoparticles. Applying a combination of highresolution imaging and in situ solid-state nuclear magnetic resonance spectroscopy, we reveal the underlying mechanism of the solid-state phase transformation of these amorphous nanoparticles into crystals under aqueous conditions. These amorphous nanoparticles are covered by a hydration shell of bound water molecules. Fast chemical exchanges occur: the hydrogens present within the nanoparticles exchange with the hydrogens from the surfacebound $\mathrm{H}_{2} \mathrm{O}$ molecules which, in turn, exchange with the hydrogens of the free $\mathrm{H}_{2} \mathrm{O}$ molecule of the surrounding aqueous medium. This cascade of chemical exchanges is associated with an enhanced mobility of the ions/molecules that compose the nanoparticles which, in turn, allow for their rearrangement into crystalline domains via solid-state transformation. Concurrently, the starting amorphous nanoparticles aggregate, and form ordered mineral structures through crystal growth by particle attachment. Sphere-like aggregates and spindleshaped structures were respectively formed from relatively high or low weights per volume of the same starting amorphous nanoparticles. These results offer promising prospects for exerting control over such a non-classical pathway to crystallization to design mineral structures that could not be achieved through classical ion-by-ion growth. 
Main text:

Exerting control over non-classical pathways to crystallization to direct the growth, polymorphism, and self-assembly of inorganic nanoparticles into higher-order structures is an important goal of materials sciences, writ large ${ }^{1-9}$. To achieve this, the dominant strategy is to govern the initial nucleation stage in a multitude of precipitation reactions occurring far from thermodynamic equilibrium ${ }^{10}$. These reactions share the common purpose of converting solution precursors into solid mineral materials ${ }^{11}$ and use various approaches to overcome the free-energy barrier to nucleation. In the case of calcium carbonate and calcium phosphate minerals, these approaches were initially implemented to uncover the biomineralization processes being used by marine calcifiers and vertebrates to allow support ${ }^{12}$, mastication ${ }^{13}$, defense ${ }^{14}$, attack ${ }^{15}$, or optical ${ }^{16}$ functions. They span from the utilization of (i) supersaturated concentrations ${ }^{17-19}$ sometimes combined with (ii) confinement effects ${ }^{20-23}$, the use of (iii) templates for epitaxial growth ${ }^{24}$, and of (iv) various types of mineralizationdirecting agents such as synthetic polyelectrolytes ${ }^{25-29}$, proteins ${ }^{30-34}$ and amino acids ${ }^{35-37}$. The future exploitation of stable pre-nucleation clusters ${ }^{38-40}$ may offer additional prospects for exerting some control over various non-classical crystallization processes ${ }^{41,42}$. Some of the above mentioned approaches were successfully applied to design and manufacture different nature-inspired inorganic-organic composite materials ${ }^{43-48}$; however, they suffer from two main limitations. First, they often lead to final materials which are very limited in terms of size (generally not exceeding a few millimeters along one dimension). Second, the level of mineralization does not reach those of their natural analogues, principally bone and nacre. The latter is the main limitation that prevents the fabrication of high strength materials. Here we consider an alternative strategy that overcome these limitations and allow the manufacturing of novel materials. Future approaches likely will skip over the initial nucleation stage on which little control can be exercised, and focus on the conversion of solid, 
metastable amorphous nanoparticles into their crystalline counterparts. Such metastable amorphous nanoparticles that assemble and transform into higher-order, hierarchical mineral structures have been observed across various biomineralizing taxa ${ }^{49-59}$, but their use in synthetic systems remains extremely limited ${ }^{60-64}$. Here we used Amorphous Calcium Magnesium Carbonate (ACMC) nanoparticles as models since most biogenic deposits of amorphous $\mathrm{CaCO}_{3}$ contain $\mathrm{Mg}^{2+}$ ions ${ }^{49,65,66}$. Especially, we monitored their pathway to crystallization in wet conditions to understand their potential use in the development of novel materials. To this end, we applied a combination of high-resolution imaging and in situ solidstate nuclear magnetic resonance (NMR) spectroscopy. In particular, the latter technique provides unprecedented atomic-scale insights into the mechanism of phase transformation of these amorphous nanoparticles over time.

\section{Chemical structure and composition}

A number of physical characterization techniques were applied to assess the structure and composition of a ${ }^{13} \mathrm{C}$-labelled $\left(98\right.$ atom\% ${ }^{13} \mathrm{C}$ ) Amorphous Calcium Magnesium Carbonate (ACMC) sample. This sample was first studied in dry conditions. Powder X-ray diffraction observations confirm that this is a non-crystalline solid given the absence of Bragg reflections (Fig. S1). According to TGA measurements (Fig. S2), the mass fraction of the hydrous species associated with the particles of ACMC is in the range of 22 to $26 \mathrm{wt}$ \% $\%$. An average atomic $\mathrm{Ca} / \mathrm{Mg}$ ratio $\approx 4.0$ was estimated using energy-dispersive $\mathrm{X}$-ray spectroscopy (EDS). As such, the atom\% of $\mathrm{Mg}$ in $\mathrm{ACMC}$ [defined as $\mathrm{Mg} /(\mathrm{Ca}+\mathrm{Mg}) \times 100$ ] is about 20.0 . This is similar to the value found in a number of biogenic deposits of amorphous calcium carbonate such as those in the cuticles and gastroliths in crustaceans, along with those in the spicules in cnidarians ${ }^{65}$. Scanning Helium Ion Microscopy (SHIM) observations show that $\mathrm{ACMC}$ is in the form of spherical nanosized particles with a diameter of about 60 to $90 \mathrm{~nm}$ 
(Fig. 1A). These features resemble those of biogenic, magnesium-rich, amorphous calcium carbonate particles present at early stages of coral biomineralization (Fig. 1B).

Solid-state Nuclear Magnetic Resonance (ssNMR) spectroscopy was applied to investigate the carbon and hydrogen chemical environments of ACMC. One dimensional (1D) $\left\{{ }^{1} \mathrm{H}\right\}{ }^{13} \mathrm{C}$ cross polarization (CP) (solid lines), and ${ }^{13} \mathrm{C}$ single-pulse (SP) (doted lines) magic angle spinning (MAS) ssNMR spectra of ACMC are shown in Fig. S3. Both spectra are in the form of a single, symmetric resonance whose carbon chemical shift $\left[\delta\left({ }^{13} \mathrm{C}\right)=168.2 \mathrm{ppm}\right]$, full width at half maximum $(\mathrm{FWHM}=3.9 \mathrm{ppm})$ and Gaussian lineshape are characteristic of carbonate ions $\left(\mathrm{CO}_{3}{ }^{2-}\right)$ present in amorphous environments. This carbon chemical shift is similar with that of calcite ${ }^{67}$ which suggests that the present sample may be considered as a proto-calcite amorphous calcium carbonate ${ }^{68}$. Further, the resonance in the ${ }^{13} \mathrm{C}$ SP spectrum is identical with the one in the $\left\{{ }^{1} \mathrm{H}\right\}{ }^{13} \mathrm{C} \mathrm{CP}$ spectrum in terms of lineshape and linewidth: $\delta\left({ }^{13} \mathrm{C}\right)=168.2 \mathrm{ppm}$ and full $\mathrm{FWHM}=3.9 \mathrm{ppm}$. This statement stands true regardless the $\mathrm{CP}$ contact time $\left(\mathrm{t}_{\mathrm{CP}}\right)$ as shown in Fig. $\mathbf{S 4}$ where $\mathrm{t}_{\mathrm{CP}}$ was varied from 0.2 to $10 \mathrm{~ms}$. The $\left\{{ }^{1} \mathrm{H}\right\}^{13} \mathrm{C}$ $\mathrm{CP}$ spectrum selectively exposes ${ }^{13} \mathrm{C}$ nuclei nearby ${ }^{1} \mathrm{H}$ nuclei that belong to different rigid hydrogen-bearing ions/molecules, whereas the ${ }^{13} \mathrm{C}$ SP spectrum reveals all ${ }^{13} \mathrm{C}$ nuclei since it was recorded in quantitative conditions. Indeed, a long relaxation delay (RD) of 600 seconds was chosen to allow for full relaxation of the longitudinal magnetization. According to their similarity in terms of lineshape and linewidth, the $\left\{{ }^{1} \mathrm{H}\right\}{ }^{13} \mathrm{C} \mathrm{CP}$ spectrum exposes similar ${ }^{13} \mathrm{C}$ nuclei as those observed upon direct excitation in the quantitative ${ }^{13} \mathrm{C} \mathrm{SP}$ spectrum. These observations provide important structural and chemical information. First, this is evidence that the rigid hydrogen-bearing ions/molecules are homogenously distributed throughout the amorphous calcium carbonate nanoparticles; and a similar conclusion was previously reached by others ${ }^{68,69}$. Second, this also rules out the presence of bicarbonate ions $\left(\mathrm{HCO}_{3}{ }^{-}\right)$given the 
absence of a distinct upfield signal at short contact time (expected in the range of $\delta\left({ }^{13} \mathrm{C}\right) \approx$ $155-165$ ppm $\left.^{67,70,71}\right)$

To reveal the nature of the hydrogen-bearing ions/molecules present in the amorphous nanoparticles, further ${ }^{1} \mathrm{H}$-based ssNMR experiments were applied. The $1 \mathrm{D}{ }^{1} \mathrm{H}$ direct excitation (DE) MAS ssNMR spectrum of ACMC is shown in Fig. S5A. However, this spectrum exposes a broad signal centered around $\delta\left({ }^{1} \mathrm{H}\right)=4.9 \mathrm{ppm}$ along with two narrow resonances at $\delta\left({ }^{1} \mathrm{H}\right)=1.2$ and $3.6 \mathrm{ppm}$ respectively, respectively due to the presence of water and mobile ethanol molecules weakly adsorbed onto the surface of the particles. The latter originate from anhydrous ethanol that was used post-precipitation to allow preservation of the solid as an amorphous phase upon storage. As an alternative, we recorded a $1 \mathrm{D}\left\{{ }^{1} \mathrm{H}_{-}{ }^{13} \mathrm{C}\right\}{ }^{1} \mathrm{H}$ double cross polarization (CP) MAS ssNMR experiment (Fig. S5B). It gives rise to a ${ }^{13} \mathrm{C}$ filtered ${ }^{1} \mathrm{H}$ spectrum whose signals correspond to structural hydrogen-bearing ions/molecules present within the amorphous nanoparticles. This approach was successfully used to investigate the hydrogen-bearing ions/molecules present in bone mineral in intact bone tissue ${ }^{72}$. Here two main resonances are clearly observable. According to their respective chemical shift, they reflect the presence of hydroxyl ions $\left(\mathrm{OH}^{-}\right)$[observable at $\delta\left({ }^{1} \mathrm{H}\right)=1.0 \mathrm{ppm}{ }^{73,74}$ ] and structural water molecules [observable at $\delta\left({ }^{1} \mathrm{H}\right)=5.6 \mathrm{ppm}$ ]. In addition, the apparent dissymmetry of the main water resonance suggests the presence of a broad downfield signal that spreads up to $\delta\left({ }^{1} \mathrm{H}\right) \approx 13 \mathrm{ppm}$ (black arrow). Further, the fact that the ${ }^{13} \mathrm{C}$-filtered ${ }^{1} \mathrm{H}$ spectrum cannot be satisfactory fitted with only two peaks at $\delta\left({ }^{1} \mathrm{H}\right)=1.0 \mathrm{ppm}\left(\mathrm{OH}^{-}\right)$and 5.6 ppm $\left(\mathrm{H}_{2} \mathrm{O}\right)$ confirms the presence of this additional broad signal (Fig. S6A). In contrast, the same ${ }^{13} \mathrm{C}$-filtered ${ }^{1} \mathrm{H}$ spectrum can be properly fitted with three peaks at $\delta\left({ }^{1} \mathrm{H}\right)=1.0 \mathrm{ppm}\left(\mathrm{OH}^{-}\right.$ ), $5.6 \mathrm{ppm}\left(\mathrm{H}_{2} \mathrm{O}\right)$ and $7.0 \mathrm{ppm}$ (Fig. S6B). The use of a single peak centered at $\delta\left({ }^{1} \mathrm{H}\right)=7.0$ ppm to materialize the additional broad signal is somewhat arbitrary. Indeed, this broad signal is probably composed of heterogeneous hydrogen environments leading to a wide distribution 
of NMR chemical shifts. However, the fact that this broad signal is centered at $\delta\left({ }^{1} \mathrm{H}\right)=7.0$ ppm suggests the presence of structural water molecules engaged in stronger hydrogen bonds than those observed at $\delta\left({ }^{1} \mathrm{H}\right)=5.6 \mathrm{ppm}{ }^{75}$.

\section{Kinetics of crystallization}

Time resolved, in situ ssNMR experiments were undertaken to investigate the kinetics of crystallization of ACMC under aqueous conditions. To this end, the amorphous powder was soaked in deionized water. Following this, $1 \mathrm{D}^{13} \mathrm{C}$ single-pulse (SP) MAS ssNMR spectra were recorded consecutively. After a period of approximately $1 \mathrm{~h}$, a second carbon resonance appears, and its intensity increases over time (Fig. 2A). This second carbon resonance is narrow $(\mathrm{FWHM}=0.70 \mathrm{ppm})$ and centered at $\delta\left({ }^{13} \mathrm{C}\right)=171.7 \mathrm{ppm}$, and, hence, reflects the growth of monohydrocalcite (MHC, calcium carbonate monohydrate: $\left.\mathrm{CaCO}_{3} \cdot \mathrm{H}_{2} \mathrm{O}\right){ }^{67}$.

Monohydrocalcite is one of the six crystalline forms of calcium carbonate. It is deposited in a variety of sedimentary environments (e.g., lakes ${ }^{76}$ and speleothems $\left.{ }^{77}\right)$. Monohydrocalcite is also the result of a number of biomineralization processes including otoliths of vertebrates ${ }^{78}$, calcareous corpuscles of certain flatworms ${ }^{79}$ and guinea pig bladder stones ${ }^{80}$. Further, monohydrocalcite could also be a metastable intermediate phase in the formation of both aragonite and calcite ${ }^{81,82}$. It is well documented that amorphous calcium carbonates are metastable and spontaneously crystallize in water. Especially if crystallization occurs via solid-state transformation (which is discussed in the next section), one could expect here the formation of calcite since ACMC may be considered as a proto-calcite amorphous calcium carbonate (Fig. S3). However, it is also well documented that magnesium regulates the crystallization of amorphous calcium carbonates ${ }^{83,84}$ and, in certain conditions, favors the formation of monohydrocalcite ${ }^{81,82,85-87}$. Here the consecutive ${ }^{13} \mathrm{C}$ SP MAS ssNMR spectra were recorded under quantitative conditions (recycling delay, $\mathrm{RD}=600 \mathrm{~s}$ ). As such, they allow for determining the conversion rate of the starting amorphous environments into 
monohydrocalcite as a function of time (Fig. 2B). This conversion rate is here expressed in terms of the molar percentage of carbonate ions present in monohydrocalcite environments. To achieve this, the consecutive ${ }^{13} \mathrm{C}$ SP MAS ssNMR spectra were all fitted with two peaks as shown in Fig. S7. The area under each peak was integrated to obtain the molar ratio of carbonate ions present in crystalline and amorphous environments. As a result, here we show that nearly $40 \%$ of the carbonate ions of ACMC were converted into monohydrocalcite after a period of about $20 \mathrm{~h}$.

\section{Solid-state phase transformation versus dissolution-reprecipitation?}

To shed light on the phase transformation process of ACMC into monohydrocalcite, a two-dimensional (2D) ${ }^{13} \mathrm{C}-{ }^{13} \mathrm{C}$ Dipolar Assisted Rotational Resonance (DARR) MAS ssNMR experiment was performed (Fig. 3A). To this end, the amorphous powder was soaked in water until its conversion rate into monohydrocalcite reached about $30 \%$, which took approximately $12 \mathrm{~h}$ (Fig. 2B). The $2 \mathrm{D}{ }^{13} \mathrm{C}-{ }^{13} \mathrm{C}$ DARR MAS ssNMR spectrum is in the form of a ${ }^{13} \mathrm{C}-{ }^{13} \mathrm{C}$ correlation map in which off-diagonal signals are due to magnetization exchange between nearby ${ }^{13} \mathrm{C}$ nuclei. Here a strong off-diagonal signal (red dotted lines) connects the carbonate ions present in monohydrocalcite [observable at $\delta\left({ }^{13} \mathrm{C}\right)=171.7 \mathrm{ppm}$ ] with those present in the amorphous environments [observable at $\delta\left({ }^{13} \mathrm{C}\right)=168.2 \mathrm{ppm}$ ]. As a consequence, these results clearly suggest that the nascent crystalline environments together with the starting amorphous environments belong to the same particles. This is strong evidence that the starting amorphous nanoparticles transform into monohydrocalcite via a mechanism of solid-state phase transformation.

An alternative scenario would see first the dissolution of the starting amorphous nanoparticles followed by their reprecipitation into monohydrocalcite. Indeed, using various methods [including isotopic labelling ${ }^{88}$, in situ liquid cell transmission electron microscopy (TEM) ${ }^{89}$ and Raman spectroscopy ${ }^{82}$, time resolved scanning electron microscopy (SEM) ${ }^{86}$, 
pH and supersaturation measurements ${ }^{90}$, Energy Dispersive X-ray Diffraction (ED-XRD) ${ }^{91}$, small and wide angle X-ray scattering (SAXS/WAXS) ${ }^{81,92}$, or the combination of several of these techniques], various mechanisms including steps of dissolution-reprecipitation were pointed out in the pathway to crystallization of different nanoparticles of synthetic amorphous calcium carbonates into calcite, magnesian calcite, aragonite, vaterite and even monohydrocalcite. Why under certain conditions some types of nanoparticles of amorphous calcium carbonate crystalize via solid-state transformation while some others first dissolve and then reprecipitate is still unclear. This major discrepancy is certainly multifactorial, depending on the polymorph and the chemical composition of the starting amorphous particles together the chemistry of the reaction solution. In this direction, a recent study suggests that the presence of $\mathrm{Mg}^{2+}$ ions incorporated in the solid phase brings excess structural water which, in turn, "weakens the ionic binding network" and favors a solid-state transformation ${ }^{89}$. In addition, it was also reported that an increased water content accelerates the mechanism of solid-state transformation in the case of a temperature-induced crystallization ${ }^{93,94}$. As such, it is important to rule out the eventuality of a mechanism of dissolution-reprecipitation during the crystallization of ACMC in the present study. To this end, we simulated a mechanism of dissolution-reprecipitation using a physical mixture containing 40 wt. \% monohydrocalcite particles and $60 \mathrm{wt} . \%$ amorphous particles soaked in water. The former particles originate from a new ${ }^{13} \mathrm{C}$-labelled $\left(99\right.$ atom $\left.\%{ }^{13} \mathrm{C}\right)$ monohydrocalcite sample (MHC) (whose powder X-ray diffraction pattern is shown in Fig. S8) that was prepared by a direct precipitation method ${ }^{85}$, whereas the latter particles are those of the amorphous ACMC sample. The ${ }^{13} \mathrm{C}-{ }^{13} \mathrm{C}$ DARR MAS ssNMR spectrum of this physical mixture soaked in water is shown in Fig. 3B. This spectrum was recorded within 90 minutes following the wetting step so that the conversion rate of ACMC into monohydrocalcite remains very low (must be below $\approx 2 \%$ - Fig. $2 B$ ). As expected, here the absence of off- 
diagonal signal confirms that the carbonate ions present in the monohydrocalcite environments of MHC are not in proximity with those present in the amorphous environments of ACMC. As such, the observation of an off-diagonal signal in the ${ }^{13} \mathrm{C}-{ }^{13} \mathrm{C}$ DARR MAS ssNMR spectrum of the ACMC sample partially converted into monohydrocalcite excludes a mechanism of dissolution-reprecipitation (Fig. 3A).

\section{Surface hydration shell and Hydrogen-Hydrogen chemical exchanges}

The possible interactions of the amorphous nanoparticles of ACMC with water molecules were examined. To this end, 2D $\left\{{ }^{1} \mathrm{H}\right\}{ }^{13} \mathrm{C}$ HetCor MAS ssNMR experiments of ACMC were performed both in dry and wet conditions (Fig. 4). In wet conditions, the sample was soaked in water and the 2D $\left\{{ }^{1} \mathrm{H}\right\}{ }^{13} \mathrm{C}$ HetCor MAS ssNMR experiment was performed within one hour following the wetting step. In these conditions, monohydrocalcite has yet not been formed, or rather remains below the detection threshold of ssNMR (Fig. 2B). These 2D $\left\{{ }^{1} \mathrm{H}\right\}{ }^{13} \mathrm{C}$ HetCor MAS ssNMR spectra are in the form of ${ }^{1} \mathrm{H}_{-}{ }^{13} \mathrm{C}$ correlation maps in which the different signals, named "correlation peaks", reveal atomic-scale spatial proximities among rigid hydrogen-bearing ions/molecules (displayed along the vertical, indirect ${ }^{1} \mathrm{H}$ dimension) and carbon-bearing ions (displayed along the horizontal, direct ${ }^{13} \mathrm{C}$ dimension). In dry conditions, a broad signal associated with two intense spinning sidebands are observable. This signal results from the juxtaposition of two different correlation peaks which, similarly to the $\left\{{ }^{1} \mathrm{H}_{-}{ }^{13} \mathrm{C}\right\}{ }^{1} \mathrm{H}$ double cross polarization (CP) MAS ssNMR experiment, are due to the presence of $\mathrm{OH}^{-}$ions [observable at $\delta\left({ }^{1} \mathrm{H}\right) \approx 1.0 \mathrm{ppm}$ ] and structural water molecules [observable in the range of $\left.\delta\left({ }^{1} \mathrm{H}\right) \approx 5-13 \mathrm{ppm}\right]$. In contrast, in wet conditions, only a single and sharp correlation peak is observable while the two intense spinning sidebands are no longer observable. This sharp correlation peak is at $\delta\left({ }^{1} \mathrm{H}\right)=4.7 \mathrm{ppm}(\mathrm{FWHM}=0.6 \mathrm{ppm})$ in the indirect ${ }^{1} \mathrm{H}$ dimension, and, hence, reflects the presence of water molecules. Since Brownian motion averages dipolar couplings to zero, these water molecules must be adsorbed onto the particles' surface to allow 
CP magnetization transfer. We can infer from this that a hydration shell of bound water forms around the particles of ACMC under aqueous conditions.

Further, the fact that the broad isotropic signal seen in dry conditions is no longer observed in wet conditions where only a sharp water correlation peak is present (Fig. 4), is diagnostic of a fast hydrogen exchange regime on the NMR time scale. Indeed, this is evidence that fast chemical exchanges occur between hydrogens from the free water molecules and those from the rigid hydrogen-bearing ions/molecules (i.e., $\mathrm{OH}^{-}$and $\mathrm{H}_{2} \mathrm{O}$ ) present in the amorphous solid. Due to the presence of the hydration shell of bound water, these chemical exchanges are likely to occur in two steps: the hydrogens present in the amorphous solid phase exchange with the hydrogens from the surface-bound $\mathrm{H}_{2} \mathrm{O}$ molecules which, in turn, exchange with the hydrogens of the free $\mathrm{H}_{2} \mathrm{O}$ molecule of the surrounding aqueous medium. Our TGA measurements (Fig. S2) show that, in dry conditions, the mass fraction of the different populations of hydrogen-bearing ions/molecules $\left(\mathrm{OH}^{-}\right.$and $\left.\mathrm{H}_{2} \mathrm{O}\right)$ associated with the particles of ACMC is in the range of 22 to 26 wt. \%. As a result, we could calculate the proportion of hydrogens originating from the particles over the total number of hydrogens present in the MAS rotor following the wetting step: i.e., from about 5 to $10 \%$. The number of hydrogens from the free water molecules is therefore in large excess over the number of hydrogens present in the particles and, hence, the latter are not detected in wet conditions (fast exchange regime) and solely the excess water signal is observed at $\delta\left({ }^{1} \mathrm{H}\right)=$ 4.7 ppm. In addition, the fact that the two intense spinning sidebands observed in dry conditions are no longer observable when the particles are soaked in water also advocate for chemical exchanges. This is evidence that the hydrogens from the particles were mobilized in wet conditions due to their exchanges with the hydrogens from the free water molecules. Further, similar hydrogen-hydrogen exchanges were also pointed out not only for synthetic 
particles of amorphous calcium phosphate (ACP) soaked in water, but also for the ACP-like surface of bone mineral particles from a fresh and intact bone tissue sample ${ }^{95}$.

For further evidence of the presence of a hydration shell of bound water, cryogenic transmission electron microscopy (cryo-TEM) observations were obtained from the amorphous nanoparticles of ACMC dispersed in water (Fig. S9). This dispersion was cryofixed in liquid ethane within 10 min after its preparation and, hence, crystallization has not yet started. A low magnification micrograph shows aggregates of nanoparticles that were highlighted by yellow circles in Fig. S9A. Regions immediately around these aggregates appear darker, indicating that the amorphous ice is thicker. This is evidence that the nanoparticles (shown at higher magnification in Fig. S9B) retain water. Further, when these nanoparticles are not "piled up" on top of each other as those pointed out with yellow arrows in Fig. S9B, tiny lighter zones are visible and are certainly due to the presence of pores. These pores are almost certainly not artifacts caused by electron beam irradiation since they do not evolve upon prolonged observation. As a result, we suggest that the pores facilitate the fast hydrogen-hydrogen exchanges that we observed in the $2 \mathrm{D}\left\{{ }^{1} \mathrm{H}\right\}{ }^{13} \mathrm{C}$ MAS HetCor ssNMR experiments performed in wet conditions.

To better understand the origin of the hydrophilic properties of ACMC, we examined whether a surface hydration shell can also form around the particles of a hydrated calcium carbonate mineral soaked in water. To this end, the MHC sample was used since monohydrocalcite $\left(\mathrm{CaCO}_{3} \cdot \mathrm{H}_{2} \mathrm{O}\right.$, with one water molecule per calcium carbonate group) is a suitable model mineral for amorphous calcium carbonates in terms of chemical composition ${ }^{96}$. The ${ }^{13} \mathrm{C}$ single-pulse (SP) MAS ssNMR spectrum of MHC is shown in Fig. S10A. This sample is mainly composed of monohydrocalcite environments, but also contains residual amorphous environments that were not converted into monohydrocalcite (Fig. S10B). Further, the 1D $\left\{{ }^{1} \mathrm{H}^{13} \mathrm{C}\right\}{ }^{1} \mathrm{H}$ double cross polarization (CP) MAS ssNMR spectrum of MHC is shown 
in Fig. S10C. This spectrum exposes a single, symmetric resonance [centered at $\delta\left({ }^{1} \mathrm{H}\right)=6.0$ $\mathrm{ppm} ; \mathrm{FWHM}=8.9 \mathrm{ppm}]$ attributed to structural water molecules in monohydrocalcite environments. As for the possible interactions of the particles of MHC with water molecules, they were investigated in a similar manner as for ACMC. Two-dimensional $\left\{{ }^{1} \mathrm{H}\right\}{ }^{13} \mathrm{C}$ HetCor MAS ssNMR experiments of MHC were performed both in dry and wet conditions and are shown in Fig S11. The signal due to the presence of the residual amorphous environments differs in dry and wet conditions. While this signal is broad and barely visible is dry conditions (grey arrow), it is clearly detected in wet conditions where a sharp correlation peak at $\delta\left({ }^{1} \mathrm{H}\right)=4.7 \mathrm{ppm}$ in the indirect ${ }^{1} \mathrm{H}$ dimension shows the presence of surface-bound water molecules. In contrast, the signal due to the presence of the monohydrocalcite environments was unchanged after hydration. In both dry and wet conditions, this signal is in the form of a broad correlation peak due to the presence of $\mathrm{CO}_{3}{ }^{2-}$ ions [observable at $\delta\left({ }^{13} \mathrm{C}\right)=171.7 \mathrm{ppm}$ in the direct ${ }^{13} \mathrm{C}$ dimension] near structural $\mathrm{H}_{2} \mathrm{O}$ molecules [centered at $\delta\left({ }^{1} \mathrm{H}\right)=6.0 \mathrm{ppm}$ in the indirect ${ }^{1} \mathrm{H}$ dimension]. As such, contrary to the amorphous environments of MHC but also those of ACMC, the presence of an excess of free water in the MAS rotor does not cause the formation of a hydration shell of bound water associated with the monohydrocalcite environments. These results suggest that the hydrophilic properties of ACMC are not due to a specific chemical composition including $\mathrm{Ca}^{2+}$ and $\mathrm{CO}_{3}{ }^{2-}$ ions along with structural $\mathrm{H}_{2} \mathrm{O}$ molecules, but are rather the result of a definite amorphous structure.

\section{Evolution of the hydrogen chemical environments as crystallization progresses}

The evolution of the hydrogen chemical environments during the conversion of the starting amorphous nanoparticles into monohydrocalcite was also scrutinized. To this end, additional 2D $\left\{{ }^{1} \mathrm{H}\right\}{ }^{13} \mathrm{C}$ HetCor MAS ssNMR experiments of ACMC soaked in water were therefore undertaken consecutively following the initial wetting step (Fig. 5). The previously mentioned, quantitative $1 \mathrm{D}^{13} \mathrm{C}$ SP MAS ssNMR spectra, were recorded between each of 
these 2D $\left\{{ }^{1} \mathrm{H}\right\}{ }^{13} \mathrm{C}$ HetCor experiments so that the molar percentage of monohydrocalcite is known. Here the growth of monohydrocalcite appears in the form of a broad, composite signal along the vertical, indirect ${ }^{1} \mathrm{H}$ dimension whose intensity progressively increases [observable at $\delta\left({ }^{13} \mathrm{C}\right)=171.7 \mathrm{ppm}$ in the horizontal, direct ${ }^{13} \mathrm{C}$ dimension]. This broad, composite signal is also observable in the ${ }^{1} \mathrm{H}$ slices taken at the monohydrocalcite position (Fig. S12A). The signal arises from hydrogen-bearing ions/molecules present within the nascent crystalline environments and spreads from $\delta\left({ }^{1} \mathrm{H}\right) \approx-5$ to $15 \mathrm{ppm}$; this is in agreement with the ${ }^{13} \mathrm{C}$-filtered ${ }^{1} \mathrm{H}$ MAS NMR spectrum of the reference sample of monohydrocalcite shown in Fig. S10C. Moreover, intense spinning sidebands, signature of hydrogen-bearing ions/molecules with restricted mobility, are also observed in agreement with the crystalline nature of these nascent environments (Fig. S12A).

As for the starting amorphous environments, a sharp water correlation peak not associated with any spinning sidebands (which is diagnostic of a fast hydrogen exchange regime on the NMR time scale $)$ is visible at the ACMC position [i.e., $\delta\left({ }^{13} \mathrm{C}\right)=168.2 \mathrm{ppm}$ in the horizontal, direct ${ }^{13} \mathrm{C}$ dimension] (Fig. 5). As a result, the ${ }^{1} \mathrm{H}$ slices taken at the ACMC position only expose a single and narrow resonance [centered at $\delta\left({ }^{1} \mathrm{H}\right)=4.7 \mathrm{ppm} ; \mathrm{FWHM}$ in the range of 0.6 to $1.3 \mathrm{ppm}$ ] attributed to water molecules bound to the particles' surface (Fig.

S12B). These observations are similar to what is observed for ACMC in wet conditions before crystallization (Fig. 4B), and highlight that the starting amorphous environments remain hydrated while crystallization progresses. They also imply that the hydrogen-bearing ions/molecules remaining in the starting amorphous environments keep undergoing chemical exchanges with the free water molecules as crystallization progresses.

\section{Hydrogen-deuterium chemical exchanges}

For further evidence of these chemical exchanges, 2D $\left\{{ }^{1} \mathrm{H}\right\}{ }^{13} \mathrm{C}$ HetCor MAS ssNMR experiments of ACMC soaked in heavy water $\left(\mathrm{D}_{2} \mathrm{O}-99.99\right.$ atom\% D) were undertaken 
sequentially (Fig. 6). Quantitative 1D ${ }^{13} \mathrm{C}$ SP MAS ssNMR spectra were recorded between each of the 2D $\left\{{ }^{1} \mathrm{H}\right\}{ }^{13} \mathrm{C}$ HetCor experiments so that the conversion rate of ACMC into monohydrocalcite is known. Here this conversion rate reaches up 26\% after 1130 minutes which is therefore about $40 \%$ lower than in the case of ACMC soaked in $\mathrm{H}_{2} \mathrm{O}$ at the same stage (conversion rate, 36\%) (Fig. 2B); and this discrepancy is likely related to a kinetic isotope effect. In contrast to the successive 2D $\left\{{ }^{1} \mathrm{H}\right\}{ }^{13} \mathrm{C}$ HetCor MAS ssNMR spectra of ACMC soaked in $\mathrm{H}_{2} \mathrm{O}$ where a broad, composite signal was observed along the indirect ${ }^{1} \mathrm{H}$ dimension, here the growth of monohydrocalcite appears in the form of a single, narrow correlation peak [observable at $\delta\left({ }^{13} \mathrm{C}\right)=171.7 \mathrm{ppm}$ in the horizontal, direct ${ }^{13} \mathrm{C}$ dimension]. The ${ }^{1} \mathrm{H}$ slices taken at the monohydrocalcite position reveal a single, symmetric resonance [centered at $\delta\left({ }^{1} \mathrm{H}\right)=6.0 \mathrm{ppm} ; \mathrm{FWHM}=2.2 \mathrm{ppm}$ ] (Fig. S13A); this chemical shift is characteristic of structural water molecules in monohydrocalcite environments (Fig. S10C). However, the associated linewidth is much smaller due to a reduction of the ${ }^{1} \mathrm{H}$ dipolar couplings induced by a partial deuteration. Indeed, here ${ }^{1} \mathrm{H} /{ }^{2} \mathrm{H}$ chemical exchanges led to the deuteration of the hydrogen-bearing ions/molecules present in the starting amorphous nanoparticles before crystallization occurs (after about $1 \mathrm{~h}$ - Fig. 2B). As a result, the protium isotopes, originating from ACMC, were diluted following the addition of the large excess of deuterium isotopes originating from the $\mathrm{D}_{2} \mathrm{O}$ solution $\left[{ }^{2} \mathrm{H} /\left({ }^{2} \mathrm{H}+{ }^{1} \mathrm{H}\right) \geq 90\right.$ atom $\%$ in the MAS rotor]. This "isotopic dilution" has largely lowered the magnitude of the homonuclear ${ }^{1} \mathrm{H}-{ }^{1} \mathrm{H}$ dipolar couplings within the particles which, in turn, gave rise to ${ }^{1} \mathrm{H}$ spectra of the monohydrocalcite environments with higher resolution (compared with $\mathrm{H}_{2} \mathrm{O}$ ). The same phenomenon also explains the presence of weaker spinning sidebands associated with the nascent crystalline environments growing in D2O compared to $\mathrm{H}_{2} \mathrm{O}$ (Fig. S13A). As for the starting amorphous environments, the sharp water correlation peak that was previously seen at $\delta\left({ }^{1} \mathrm{H}\right)=4.7 \mathrm{ppm}(\mathrm{FWHM}$ in the range of 0.6 to $1.3 \mathrm{ppm})$ along the indirect 
${ }^{1} \mathrm{H}$ dimension of the successive 2D $\left\{{ }^{1} \mathrm{H}\right\}{ }^{13} \mathrm{C}$ HetCor MAS ssNMR spectra of ACMC soaked in $\mathrm{H}_{2} \mathrm{O}$ was not observed. Instead, two narrow correlation peaks due to the presence of structural $\mathrm{OH}^{-}$ions $\left[\delta\left({ }^{1} \mathrm{H}\right)=1.0 \mathrm{ppm}\right.$ - no longer observed after $\left.330 \mathrm{~min}\right]$ and structural water molecules $\left[\delta\left({ }^{1} \mathrm{H}\right)=5.6 \mathrm{ppm} ; \mathrm{FWHM} \approx 2.9 \mathrm{ppm}\right]$ arise from the starting amorphous

environments (Fig. 6). The intensity of the water correlation peak progressively declines up to 970 minutes, after which the peak becomes almost no longer visible; this is also observable in the ${ }^{1} \mathrm{H}$ slices taken at the ACMC position [i.e., $\delta\left({ }^{13} \mathrm{C}\right)=168.2 \mathrm{ppm}$ in the direct ${ }^{13} \mathrm{C}$ dimension] (Fig. S13B). The number of hydrogens originating from the particles initially represents almost $100 \%$ of the total number of hydrogens present in the MAS rotor following the wetting step with $\mathrm{D}_{2} \mathrm{O}$. The surface-bound water molecules (mostly in the form of $\mathrm{D}_{2} \mathrm{O}$, and in a less extent $\mathrm{H}_{2} \mathrm{O}$ but also $\mathrm{HDO}$ that were formed following the chemical exchanges) are not detected in the $2 \mathrm{D}\left\{{ }^{1} \mathrm{H}\right\}{ }^{13} \mathrm{C}$ HetCor spectra due to the fast exchange regime where solely the excess $\mathrm{OH}^{-} / \mathrm{H}_{2} \mathrm{O}$ and $\mathrm{HDO}$ signals arising from the particles are observed. Further. the disappearance of these $\mathrm{OH}^{-} / \mathrm{H}_{2} \mathrm{O}$ and $\mathrm{HDO}$ signals is due to the rearrangement of these populations of hydrogen-bearing ions/molecules present in the starting amorphous environments to form of monohydrocalcite via a solid-state phase transformation (Fig. 3A).

\section{Crystal growth by accretion of amorphous nanoparticles}

The mineral structures resulting from the crystallization of ACMC soaking in water in the MAS rotor were scrutinized by Scanning Helium Ion Microscopy (SHIM). To this end, the previously mentioned, consecutive ${ }^{13} \mathrm{C}$ SP MAS ssNMR experiments of ACMC soaked in water, have been run until the signal arising from the starting amorphous environments stops evolving (after a period of approximately $2500 \mathrm{~min}$ ). Hence, at this stage, the conversion rate of ACMC into monohydrocalcite has reached its maximum (Fig. S14). Following this, the wet powder was simply collected from the MAS rotor, washed with deionized water, and then dried at ambient temperature. The resulting dry powder was analyzed by X-ray diffraction 
that has confirmed the presence of monohydrocalcite (Fig S15). From the same powder, an average atomic $\mathrm{Ca} / \mathrm{Mg}$ ratio $\approx 5.0$ was estimated using energy-dispersive $\mathrm{X}$-ray spectroscopy (EDS). It corresponds to an atom\% of $\mathrm{Mg}$ in ACMC converted into monohydrocalcite [defined as $\mathrm{Mg} /(\mathrm{Ca}+\mathrm{Mg}) \times 100$ ] of about 16.6 (against 20.0 for ACMC before crystallization). It shows that a small proportion of $\mathrm{Mg}^{2+}$ have been expelled out of the particles following crystallization. This suggests that the leading process of solid-state transformation of ACMC into monohydrocalcite is here associated with a small loss of magnesium that possibly occurs via a mechanism of Ostwald ripening ${ }^{81}$. As for the SHIM observations, a low magnification micrograph clearly shows that the crystallization process of ACMC occurs via a spherulitic growth mechanism (Fig. 7A). Successive magnification micrographs on an open spherulite reveal the presence of crystals that greatly differ from the classical view of inorganic crystals with faceted surfaces (Fig. 7, B to D). Instead, acicular crystals displaying a highly textured surface due to the apparent presence of spherical nanoparticles "building-blocks" are here observed. Similar acicular crystals are also observable at the surface of a spherulite (double yellow arrows in Fig. 7E), where the spherical nanoparticles "building-blocks" match with the starting amorphous nanoparticles of ACMC in terms of size (Fig. 7F). Such "nano-particulate" texture was initially observed for biological aragonite in nacre ${ }^{53,97}$ and more recently for biological aragonite in coral (Fig. 7G) ${ }^{49}$ and across a broad range of biomineralizing taxa ${ }^{98}$. This "nano-particulate" texture is another evidence for a mechanism of solid-state transformation; this is also signature of crystal growth by accretion of amorphous nanoparticles ${ }^{99,100}$ which is one variety of crystallization by particle attachment ${ }^{101}$.

In addition, in order to assess the behavior of ACMC within in a higher volume of water, the mineral structures resulting from the crystallization of ACMC soaking in a reaction vial instead of in an NMR rotor were also scrutinized. To this end, the amorphous 
nanoparticles of ACMC were dispersed in deionized water in a $10 \mathrm{ml}$ vial (mass concentration $\approx 2 \% \mathrm{w} / \mathrm{v}$ against about $30 \% \mathrm{w} / \mathrm{v}$ in the MAS rotor) and the resulting suspension was aged for a period of 24 hours to allow crystallization. This dispersion was then cryofixed in liquid ethane and imaged using cryogenic transmission electron microscopy (cryo-TEM). In the present conditions, sphere-like aggregates were not observed but a low magnification micrograph instead shows the presence of spindle-shaped, higher-order mineral structures (Fig. S9C). These mineral structures have a length from 800 to $1700 \mathrm{~nm}$ and a thickness from 200 to $500 \mathrm{~nm}$. At high magnification, it is clear that they are not monolithic but are rather in the form of bundles of smaller parallel units (Figs. 7H and S9D). Selected-area electrondiffraction (SAED) shows that these bundles of smaller parallel units are composed of monohydrocalcite (inset in Fig. 7H). Similar spindle-shaped mineral structures were also observed following the crystallization of amorphous calcium carbonate nanoparticles into aragonite ${ }^{102}$. In this study, nanoscale crystals formed within an "amorphous framework" composed of aggregated amorphous nanoparticles. Our results support an analogous mechanism for the crystallization of ACMC into monohydrocalcite: the amorphous nanoparticles first aggregate (Fig. S9A) and then crystalize via solid-state transformation (Figs. 3A, 7H and S9B).

\section{Chemical and structural model of the surface region}

The results presented in the present study allowed us to design a two-dimensional chemical and structural model of the surface region of an amorphous particle of ACMC soaked in water (Fig. 8B). The amorphous solid phase (grey area) is composed of homogeneously distributed, structural $\mathrm{OH}^{-}$ions and $\mathrm{H}_{2} \mathrm{O}$ molecules close to $\mathrm{CO}_{3}{ }^{2-}$ ions. Here the coordination number of the cations is arbitrary. But a ${ }^{25} \mathrm{Mg}$-based solid-state NMR study suggests that, in $\mathrm{Mg}$-stabilized amorphous calcium carbonates, each $\mathrm{Mg}^{2+}$ are surrounded by 4-4.5 $\mathrm{CO}_{3}{ }^{2-}$ ions in average along with at least one $\mathrm{H}_{2} \mathrm{O}$ molecule ${ }^{103}$. The surface of the 
nanoparticle is hydrophilic and, hence, they are covered by a hydration shell of bound water.

The assumption was made that the water molecules of the hydration shell form a second sphere of coordination around the surface ions. Fast chemical exchanges continuously occur: the hydrogens present in the amorphous solid phase exchange with the hydrogens from the surface-bound $\mathrm{H}_{2} \mathrm{O}$ molecules which, in turn, exchange with the hydrogens of the free $\mathrm{H}_{2} \mathrm{O}$ molecule of the surrounding aqueous medium. These exchanges may be facilitated due to the presence of pores (size, 1 to $3 \mathrm{~nm}$ ) seen in the cryo-TEM micrograph shown in Fig. 8A.

\section{Conclusions}

Our results reveal the underlying mechanism of the solid-state phase transformation of Amorphous Calcium Magnesium Carbonate (ACMC) nanoparticles into crystals under aqueous conditions. First, we showed that the ${ }^{13} \mathrm{C}-{ }^{13} \mathrm{C}$ Dipolar Assisted Rotational Resonance (DARR) ssNMR technique can be used to assess whether crystallization occurs via dissolution-reprecipitation or whether it occurs via solid-state transformation. Using this technique, we show that the nascent crystalline environments in the form of monohyrocalcite (MHC), together with the starting amorphous environments, belong to the same particles. This is clear evidence of a solid-state phase transformation of the starting amorphous nanoparticles into crystals. Second, we show that the surface of these amorphous nanoparticle is hydrophilic. Indeed, when soaked in aqueous medium, these nanoparticles are covered by a hydration shell of bound water (Fig. 8). As a result, when the particles come into contact following aggregation or simple sedimentation, this hydration shell drives particle-particle interactions. In a bigger picture, it is now acknowledged that "the role of hydration layers in biogenic systems needs to be considered and may be responsible for phenomena seen in biomineralization" ${ }^{104}$. Our results also show that fast chemical exchanges continuously occur: the hydrogens present in the particles exchange with the hydrogens from the hydration shell of bound water which, in turn, exchange with the hydrogens of the free $\mathrm{H}_{2} \mathrm{O}$ molecule of the 
surrounding aqueous medium. We also revealed that the starting amorphous nanoparticles remain hydrated while crystallization progresses. And while the nanoparticles are partially converted into monohydrocalcite, the domains part of the nanoparticles that remain amorphous keep undergoing fast hydrogen-hydrogen chemical exchanges with the free $\mathrm{H}_{2} \mathrm{O}$ molecules of the surrounding aqueous medium. Hence, our results question the role played by these unceasing chemical exchanges towards crystallization. While hydrogens from the amorphous nanoparticles are relocated into the surrounding aqueous medium, hydrogens from the aqueous medium travel the reverse path. As a result, H-bonds, that presumably stabilizes amorphous solids against crystallization ${ }^{105}$, are being constantly broken and reformed throughout the amorphous solid. Our results suggest that this process is associated with an enhanced mobility of the ions/molecules that compose the amorphous nanoparticles which, in turn, could allow for rearrangement of these ions/molecules into crystalline domains via solidstate transformation. Further, we can hypothesize what sometimes triggers the total dissolution of certain amorphous nanoparticles under aqueous conditions ${ }^{81,86}$ (not observed in the present study). We presume that an increased content of structural hydrous species will escalate the hydrogen-hydrogen exchanges and, concomitantly, rise the mobility of the ions/molecules that compose the amorphous nanoparticles. This mobility could reach a certain level where the amorphous nanoparticles breaks down into solubilized ions that are now available to reprecipitate into a new solid phase. From a wider perspective, our results shed light on the means available to living organisms for directing crystallization into a process of solid-state transformation rather than one of dissolution-precipitation and, as such, could help to reconstruct the puzzle of various biomineralization processes.

Last, the results presented here and elsewhere ${ }^{89,102,106,107}$ reveal the capability of synthetic, amorphous inorganic nanoparticles to form higher-order mineral structures through pathways to crystallization that combine solid-state phase transformation and particle 
493 attachment. As a such, taking advantage of these pathways to crystallization opens new

494 avenues in materials science based on future strategies that will no longer be limited by the

495 initial nucleation stage. In addition, since these pathways to crystallization also offers the 496 opportunity to shape the resulting higher-order mineral structures into different morphologies

$497{ }^{63}$ (such as the spherulitic aggregates and the spindle-shaped mineral structures shown in the 498 present study), they also pave the way for future strategies that will no longer be "restricted by 499 the constraints of the crystal unit cell" 4. 
501

502

503 support. We thank Prof. Leonard C. Feldman and Prof. Torgny Gustafsson for providing access to the scanning helium ion microscope. We also thank M. Nilges and the Equipex

CACSICE for providing the Falcon II direct detector. SVE thanks Marie Albéric and Juan Diego Rodriguez-Blanco for insightful discussions, and Kevin Wyman for daily assistance in the lab. Our research was supported by the National Science Foundation under Grant No. EF 1416785 awarded to PF, the European Union's Horizon 2020 research and innovation program under the Marie Sklodowska-Curie grant agreement No. 793861 awarded to SVE, and the Ulysses scheme of the Irish Research Council awarded to SVE and TA.

\section{Supporting Information: X-ray diffraction analysis of ACMC (Figure S1); Weight} loss and heat flow measurements of ACMC (Figure S2); Carbon environments of ACMC (Figure S3); Cross-polarization dynamics between ${ }^{1} \mathrm{H}$ and ${ }^{13} \mathrm{C}$ nuclei in ACMC (Figure S4); Hydrogen environments of ACMC (Figure S5); Rigid hydrogen-bearing ions/molecules present in ACMC (Figure S6); Evaluation of the conversion rate of ACMC into monohydrocalcite (Figure S7); X-ray diffraction analysis of the monohydrocalcite sample (Figure S8); Observations of the starting amorphous nanoparticles of ACMC and their resulting higher-order mineral structures following crystallization (Figure S9); Carbon and Hydrogen environments of the monohydrocalcite sample (Figure S10); Spatial proximities among carbon-bearing ions and hydrogen-bearing ions/molecules in the particles of the monohydrocalcite sample (Figure S11); Evolution of the hydrogen environments while the amorphous nanoparticles of ACMC are crystalizing in water (Figure S12); Evolution of the hydrogen environments while the amorphous nanoparticles of ACMC are crystalizing in heavy water (Figure S13); Carbon environments of ACMC before and after crystallization (Figure S14); X-ray diffraction analysis of ACMC following crystallization (Figure S15). 
(1) Cölfen, H.; Mann, S. Higher-Order Organization by Mesoscale Self-Assembly and Transformation of Hybrid Nanostructures. Angew. Chem. Int. Ed. 2003, 42 (21), 23502365. https://doi.org/10.1002/anie.200200562.

(2) Meldrum, F. C.; Cölfen, H. Controlling Mineral Morphologies and Structures in Biological and Synthetic Systems. Chem. Rev. 2008, 108 (11), 4332-4432. https://doi.org/10.1021/cr8002856.

(3) Imai, H. Mesostructured Crystals: Growth Processes and Features. Prog. Cryst. Growth Charact. Mater. 2016, 62 (2), 212-226. https://doi.org/10.1016/j.pcrysgrow.2016.04.011.

(4) Jehannin, M.; Rao, A.; Cölfen, H. New Horizons of Nonclassical Crystallization. J. Am. Chem. Soc. 2019, 141 (26), 10120-10136. https://doi.org/10.1021/jacs.9b01883.

(5) Rieger, J.; Kellermeier, M.; Nicoleau, L. Formation of Nanoparticles and Nanostructures-An Industrial Perspective on $\mathrm{CaCO}_{3}$, Cement, and Polymers. Angew. Chem. Int. Ed. 2014, n/a-n/a. https://doi.org/10.1002/anie.201402890.

(6) Imai, H. Self-Organized Formation of Hierarchical Structures. In Biomineralization I; Naka, K., Ed.; Springer Berlin Heidelberg, 2007; Vol. 270, pp 43-72. https://doi.org/10.1007/128_054.

(7) Cölfen, H.; Antonietti, M. Mesocrystals: Inorganic Superstructures Made by Highly Parallel Crystallization and Controlled Alignment. Angew. Chem. Int. Ed. 2005, 44 (35), 5576-5591. https://doi.org/10.1002/anie.200500496.

(8) Lee, J.; Yang, J.; Kwon, S. G.; Hyeon, T. Nonclassical Nucleation and Growth of Inorganic Nanoparticles. Nat. Rev. Mater. 2016, 1 (8), 16034. https://doi.org/10.1038/natrevmats.2016.34.

(9) Navrotsky, A. Energetic Clues to Pathways to Biomineralization: Precursors, Clusters, and Nanoparticles. Proc. Natl. Acad. Sci. 2004, 101 (33), 12096-12101. https://doi.org/10.1073/pnas.0404778101.

(10) Nakouzi, E.; Steinbock, O. Self-Organization in Precipitation Reactions Far from the Equilibrium. Sci. Adv. 2016, 2 (8), e1601144. https://doi.org/10.1126/sciadv.1601144.

(11) New Perspectives on Mineral Nucleation and Growth; Van Driessche, A. E. S., Kellermeier, M., Benning, L. G., Gebauer, D., Eds.; Springer International Publishing: Cham, 2017. https://doi.org/10.1007/978-3-319-45669-0.

(12) Reznikov, N.; Bilton, M.; Lari, L.; Stevens, M. M.; Kröger, R. Fractal-like Hierarchical Organization of Bone Begins at the Nanoscale. Science 2018, 360 (6388), eaao2189. https://doi.org/10.1126/science.aao2189.

(13) Gordon, L. M.; Cohen, M. J.; MacRenaris, K. W.; Pasteris, J. D.; Seda, T.; Joester, D. Amorphous Intergranular Phases Control the Properties of Rodent Tooth Enamel. Science 2015, 347 (6223), 746-750. https://doi.org/10.1126/science.1258950.

(14) Macías-Sánchez, E.; Willinger, M. G.; Pina, C. M.; Checa, A. G. Transformation of ACC into Aragonite and the Origin of the Nanogranular Structure of Nacre. Sci. Rep. 2017, 7 (1). https://doi.org/10.1038/s41598-017-12673-0.

(15) Weaver, J. C.; Milliron, G. W.; Miserez, A.; Evans-Lutterodt, K.; Herrera, S.; Gallana, I.; Mershon, W. J.; Swanson, B.; Zavattieri, P.; DiMasi, E.; Kisailus, D. The Stomatopod Dactyl Club: A Formidable Damage-Tolerant Biological Hammer. Science 2012, 336 (6086), 1275-1280. https://doi.org/10.1126/science.1218764.

(16) Aizenberg, J.; Tkachenko, A.; Weiner, S.; Addadi, L.; Hendler, G. Calcitic Microlenses as Part of the Photoreceptor System in Brittlestars. Nature 2001, 412 (6849), 819-822. https://doi.org/10.1038/35090573. 
(17) Nassif, N.; Martineau, F.; Syzgantseva, O.; Gobeaux, F.; Willinger, M.; Coradin, T.; Cassaignon, S.; Azaïs, T.; Giraud-Guille, M. M. In Vivo Inspired Conditions to Synthesize Biomimetic Hydroxyapatite. Chem. Mater. 2010, 22 (12), 3653-3663. https://doi.org/10.1021/cm903596q.

(18) Nebel, H.; Epple, M. Continuous Preparation of Calcite, Aragonite and Vaterite, and of Magnesium-Substituted Amorphous Calcium Carbonate (Mg-ACC). Z. Für Anorg. Allg. Chem. 2008, 634 (8), 1439-1443. https://doi.org/10.1002/zaac.200800134.

(19) Ma, M.; Wang, Y.; Cao, X.; Lu, W.; Guo, Y. Temperature and Supersaturation as Key Parameters Controlling the Spontaneous Precipitation of Calcium Carbonate with Distinct Physicochemical Properties from Pure Aqueous Solutions. Cryst. Growth Des. 2019, 19 (12), 6972-6988. https://doi.org/10.1021/acs.cgd.9b00758.

(20) Zeng, M.; Kim, Y.-Y.; Anduix-Canto, C.; Frontera, C.; Laundy, D.; Kapur, N.; Christenson, H. K.; Meldrum, F. C. Confinement Generates Single-Crystal Aragonite Rods at Room Temperature. Proc. Natl. Acad. Sci. 2018, 115 (30), 7670-7675. https://doi.org/10.1073/pnas.1718926115.

(21) Wang, Y.; Zeng, M.; Meldrum, F. C.; Christenson, H. K. Using Confinement To Study the Crystallization Pathway of Calcium Carbonate. Cryst. Growth Des. 2017, 17 (12), 6787-6792. https://doi.org/10.1021/acs.cgd.7b01359.

(22) Cantaert, B.; Beniash, E.; Meldrum, F. C. Nanoscale Confinement Controls the Crystallization of Calcium Phosphate: Relevance to Bone Formation. Chem. - Eur. J. 2013, 19 (44), 14918-14924. https://doi.org/10.1002/chem.201302835.

(23) Wang, Y.; Von Euw, S.; Laurent, G.; Crevant, C.; Bonhomme-Coury, L.; GiraudGuille, M.-M.; Babonneau, F.; Nassif, N.; Azaïs, T. Impact of Collagen Confinement vs. Ionic Substitutions on the Local Disorder in Bone and Biomimetic Apatites. Mater Horiz 2014, 1 (2), 224-231. https://doi.org/10.1039/C3MH00071K.

(24) Shao, C.; Jin, B.; Mu, Z.; Lu, H.; Zhao, Y.; Wu, Z.; Yan, L.; Zhang, Z.; Zhou, Y.; Pan, H.; Liu, Z.; Tang, R. Repair of Tooth Enamel by a Biomimetic Mineralization Frontier Ensuring Epitaxial Growth. Sci. Adv. 2019, 5 (8), eaaw9569. https://doi.org/10.1126/sciadv.aaw9569.

(25) Olszta, M. J.; Odom, D. J.; Douglas, E. P.; Gower, L. B. A New Paradigm for Biomineral Formation: Mineralization via an Amorphous Liquid-Phase Precursor. Connect. Tissue Res. 2003, 44 (1), 326-334. https://doi.org/10.1080/03008200390181852.

(26) Yao, S.; Lin, X.; Xu, Y.; Chen, Y.; Qiu, P.; Shao, C.; Jin, B.; Mu, Z.; Sommerdijk, N. A. J. M.; Tang, R. Osteoporotic Bone Recovery by a Highly Bone-Inductive Calcium Phosphate Polymer-Induced Liquid-Precursor. Adv. Sci. 2019, 6 (19), 1900683. https://doi.org/10.1002/advs.201900683.

(27) Thula, T. T.; Svedlund, F.; Rodriguez, D. E.; Podschun, J.; Pendi, L.; Gower, L. B. Mimicking the Nanostructure of Bone: Comparison of Polymeric Process-Directing Agents. Polymers 2010, 3 (1), 10-35. https://doi.org/10.3390/polym3010010.

(28) Demmert, B.; Schinzel, F.; Schüßler, M.; Mondeshki, M.; Kaschta, J.; Schubert, D. W.; Jacob, D. E.; Wolf, S. E. Polymer-Functionalised Nanograins of Mg-Doped Amorphous Calcium Carbonate via a Flow-Chemistry Approach. Materials 2019, 12 (11), 1818. https://doi.org/10.3390/ma12111818.

(29) Zou, Z.; Bertinetti, L.; Politi, Y.; Fratzl, P.; Habraken, W. J. E. M. Control of Polymorph Selection in Amorphous Calcium Carbonate Crystallization by Poly(Aspartic Acid): Two Different Mechanisms. Small 2017, 13 (21), 1603100. https://doi.org/10.1002/smll.201603100. 
(30) Ruiz-Agudo, C.; Lutz, J.; Keckeis, P.; King, M.; Marx, A.; Gebauer, D. Ubiquitin Designer Proteins as a New Additive Generation toward Controlling Crystallization. $J$. Am. Chem. Soc. 2019, 141 (31), 12240-12245. https://doi.org/10.1021/jacs.9b06473.

(31) He, G.; Dahl, T.; Veis, A.; George, A. Nucleation of Apatite Crystals in Vitro by SelfAssembled Dentin Matrix Protein 1. Nat. Mater. 2003, 2 (8), 552-558. https://doi.org/10.1038/nmat945.

(32) Gavriel, R.; Nadav-Tsubery, M.; Glick, Y.; Yarmolenko, A.; Kofman, R.; KeinanAdamsky, K.; Berman, A.; Mass, T.; Goobes, G. The Coral Protein CARP3 Acts from a Disordered Mineral Surface Film to Divert Aragonite Crystallization in Favor of MgCalcite. Adv. Funct. Mater. 2018, 28 (21), 1707321. https://doi.org/10.1002/adfm.201707321.

(33) Elsharkawy, S.; Al-Jawad, M.; Pantano, M. F.; Tejeda-Montes, E.; Mehta, K.; Jamal, H.; Agarwal, S.; Shuturminska, K.; Rice, A.; Tarakina, N. V.; Wilson, R. M.; Bushby, A. J.; Alonso, M.; Rodriguez-Cabello, J. C.; Barbieri, E.; del Río Hernández, A.; Stevens, M. M.; Pugno, N. M.; Anderson, P.; Mata, A. Protein Disorder-Order Interplay to Guide the Growth of Hierarchical Mineralized Structures. Nat. Commun. 2018, 9 (1), 2145. https://doi.org/10.1038/s41467-018-04319-0.

(34) Green, D. C.; Shida, Y.; Honma, N.; Holden, M. A.; Kim, Y.-Y.; Kulak, A. N.; Ogasawara, W.; Meldrum, F. C. Skin-Deep Surface Patterning of Calcite. Chem. Mater. 2019, 31 (21), 8725-8733. https://doi.org/10.1021/acs.chemmater.9b02421.

(35) Evans, D.; Webb, P. B.; Penkman, K.; Kröger, R.; Allison, N. The Characteristics and Biological Relevance of Inorganic Amorphous Calcium Carbonate (ACC) Precipitated from Seawater. Cryst. Growth Des. 2019, 19 (8), 4300-4313. https://doi.org/10.1021/acs.cgd.9b00003.

(36) Štajner, L.; Kontrec, J.; Njegić Džakula, B.; Maltar-Strmečki, N.; Plodinec, M.; Lyons, D. M.; Kralj, D. The Effect of Different Amino Acids on Spontaneous Precipitation of Calcium Carbonate Polymorphs. J. Cryst. Growth 2018, 486, 71-81. https://doi.org/10.1016/j.jcrysgro.2018.01.023.

(37) Tobler, D. J.; Blanco, J. D. R.; Dideriksen, K.; Sand, K. K.; Bovet, N.; Benning, L. G.; Stipp, S. L. S. The Effect of Aspartic Acid and Glycine on Amorphous Calcium Carbonate (ACC) Structure, Stability and Crystallization. Procedia Earth Planet. Sci. 2014, 10, 143-148. https://doi.org/10.1016/j.proeps.2014.08.047.

(38) Pouget, E. M.; Bomans, P. H. H.; Goos, J. A. C. M.; Frederik, P. M.; de With, G.; Sommerdijk, N. A. J. M. The Initial Stages of Template-Controlled CaCO3 Formation Revealed by Cryo-TEM. Science 2009, 323 (5920), 1455-1458. https://doi.org/10.1126/science.1169434.

(39) Gebauer, D.; Völkel, A.; Cölfen, H. Stable Prenucleation Calcium Carbonate Clusters. Science 2008, 322 (5909), 1819-1822. https://doi.org/10.1126/science.1164271.

(40) Dey, A.; Bomans, P. H. H.; Müller, F. A.; Will, J.; Frederik, P. M.; de With, G.; Sommerdijk, N. A. J. M. The Role of Prenucleation Clusters in Surface-Induced Calcium Phosphate Crystallization. Nat. Mater. 2010, 9 (12), 1010-1014. https://doi.org/10.1038/nmat2900.

(41) Gebauer, D.; Kellermeier, M.; Gale, J. D.; Bergström, L.; Cölfen, H. Pre-Nucleation Clusters as Solute Precursors in Crystallisation. Chem Soc Rev 2014, 43 (7), 23482371. https://doi.org/10.1039/C3CS60451A.

(42) Gebauer, D.; Wolf, S. E. Designing Solid Materials from Their Solute State: A Shift in Paradigms toward a Holistic Approach in Functional Materials Chemistry. J. Am. Chem. Soc. 2019, 141 (11), 4490-4504. https://doi.org/10.1021/jacs.8b13231.

(43) Wang, Y.; Azaïs, T.; Robin, M.; Vallée, A.; Catania, C.; Legriel, P.; Pehau-Arnaudet, G.; Babonneau, F.; Giraud-Guille, M.-M.; Nassif, N. The Predominant Role of 
Collagen in the Nucleation, Growth, Structure and Orientation of Bone Apatite. Nat. Mater. 2012, 11 (8), 724-733. https://doi.org/10.1038/nmat3362.

(44) Thrivikraman, G.; Athirasala, A.; Gordon, R.; Zhang, L.; Bergan, R.; Keene, D. R.; Jones, J. M.; Xie, H.; Chen, Z.; Tao, J.; Wingender, B.; Gower, L.; Ferracane, J. L.; Bertassoni, L. E. Rapid Fabrication of Vascularized and Innervated Cell-Laden Bone Models with Biomimetic Intrafibrillar Collagen Mineralization. Nat. Commun. 2019, 10 (1), 3520. https://doi.org/10.1038/s41467-019-11455-8.

(45) Wingender, B.; Bradley, P.; Saxena, N.; Ruberti, J. W.; Gower, L. Biomimetic Organization of Collagen Matrices to Template Bone-like Microstructures. Matrix Biol. 2016, 52-54, 384-396. https://doi.org/10.1016/j.matbio.2016.02.004.

(46) Volkmer, D.; Harms, M.; Gower, L.; Ziegler, A. Morphosynthesis of Nacre-Type Laminated CaCO3 Thin Films and Coatings. Angew. Chem. Int. Ed. 2005, 44 (4), 639644. https://doi.org/10.1002/anie.200461386.

(47) Mao, L.-B.; Gao, H.-L.; Yao, H.-B.; Liu, L.; Colfen, H.; Liu, G.; Chen, S.-M.; Li, S.K.; Yan, Y.-X.; Liu, Y.-Y.; Yu, S.-H. Synthetic Nacre by Predesigned Matrix-Directed Mineralization. Science 2016, 354 (6308), 107-110. https://doi.org/10.1126/science.aaf8991.

(48) Wingender, B.; Ni, Y.; Zhang, Y.; Taylor, C.; Gower, L. Hierarchical Characterization and Nanomechanical Assessment of Biomimetic Scaffolds Mimicking Lamellar Bone via Atomic Force Microscopy Cantilever-Based Nanoindentation. Materials 2018, 11 (7), 1257. https://doi.org/10.3390/ma11071257.

(49) Von Euw, S.; Zhang, Q.; Manichev, V.; Murali, N.; Gross, J.; Feldman, L. C.; Gustafsson, T.; Flach, C.; Mendelsohn, R.; Falkowski, P. G. Biological Control of Aragonite Formation in Stony Corals. Science 2017, 356 (6341), 933-938. https://doi.org/10.1126/science.aam6371.

(50) Beniash, E.; Metzler, R. A.; Lam, R. S. K.; Gilbert, P. U. P. A. Transient Amorphous Calcium Phosphate in Forming Enamel. J. Struct. Biol. 2009, 166 (2), 133-143. https://doi.org/10.1016/j.jsb.2009.02.001.

(51) Mahamid, J.; Sharir, A.; Addadi, L.; Weiner, S. Amorphous Calcium Phosphate Is a Major Component of the Forming Fin Bones of Zebrafish: Indications for an Amorphous Precursor Phase. Proc. Natl. Acad. Sci. 2008, 105 (35), 12748-12753. https://doi.org/10.1073/pnas.0803354105.

(52) Politi, Y.; Metzler, R. A.; Abrecht, M.; Gilbert, B.; Wilt, F. H.; Sagi, I.; Addadi, L.; Weiner, S.; Gilbert, P. U. P. A. Transformation Mechanism of Amorphous Calcium Carbonate into Calcite in the Sea Urchin Larval Spicule. Proc. Natl. Acad. Sci. 2008, 105 (45), 17362-17366. https://doi.org/10.1073/pnas.0806604105.

(53) DeVol, R. T.; Sun, C.-Y.; Marcus, M. A.; Coppersmith, S. N.; Myneni, S. C. B.; Gilbert, P. U. P. A. Nanoscale Transforming Mineral Phases in Fresh Nacre. J. Am. Chem. Soc. 2015, 137 (41), 13325-13333. https://doi.org/10.1021/jacs.5b07931.

(54) Beniash, E.; Aizenberg, J.; Addadi, L.; Weiner, S. Amorphous Calcium Carbonate Transforms into Calcite during Sea Urchin Larval Spicule Growth. Proc. R. Soc. Lond. B Biol. Sci. 1997, 264 (1380), 461-465. https://doi.org/10.1098/rspb.1997.0066.

(55) Weiss, I. M.; Tuross, N.; Addadi, L.; Weiner, S. Mollusc Larval Shell Formation: Amorphous Calcium Carbonate Is a Precursor Phase for Aragonite. J. Exp. Zool. 2002, 293 (5), 478-491. https://doi.org/10.1002/jez.90004.

(56) Griesshaber, E.; Kelm, K.; Sehrbrock, A.; Mader, W.; Mutterlose, J.; Brand, U.; Schmahl, W. W. Amorphous Calcium Carbonate in the Shell Material of the Brachiopod Megerlia Truncata. Eur. J. Mineral. 2009, 21 (4), 715-723. https://doi.org/10.1127/0935-1221/2009/0021-1950. 
(57) Mass, T.; Giuffre, A. J.; Sun, C.-Y.; Stifler, C. A.; Frazier, M. J.; Neder, M.; Tamura, N.; Stan, C. V.; Marcus, M. A.; Gilbert, P. U. P. A. Amorphous Calcium Carbonate Particles Form Coral Skeletons. Proc. Natl. Acad. Sci. 2017, 114 (37), E7670-E7678. https://doi.org/10.1073/pnas.1707890114.

(58) Politi, Y. Sea Urchin Spine Calcite Forms via a Transient Amorphous Calcium Carbonate Phase. Science 2004, 306 (5699), 1161-1164. https://doi.org/10.1126/science.1102289.

(59) Polishchuk, I.; Bracha, A. A.; Bloch, L.; Levy, D.; Kozachkevich, S.; Etinger-Geller, Y.; Kauffmann, Y.; Burghammer, M.; Giacobbe, C.; Villanova, J.; Hendler, G.; Sun, C.-Y.; Giuffre, A. J.; Marcus, M. A.; Kundanati, L.; Zaslansky, P.; Pugno, N. M.; Gilbert, P. U. P. A.; Katsman, A.; Pokroy, B. Coherently Aligned Nanoparticles within a Biogenic Single Crystal: A Biological Prestressing Strategy. Science 2017, 358 (6368), 1294-1298. https://doi.org/10.1126/science.aaj2156.

(60) Gal, A.; Habraken, W.; Gur, D.; Fratzl, P.; Weiner, S.; Addadi, L. Calcite Crystal Growth by a Solid-State Transformation of Stabilized Amorphous Calcium Carbonate Nanospheres in a Hydrogel. Angew. Chem. Int. Ed. 2013, 52 (18), 4867-4870. https://doi.org/10.1002/anie.201210329.

(61) Sun, R.; Willhammar, T.; Svensson Grape, E.; Strømme, M.; Cheung, O. Mesoscale Transformation of Amorphous Calcium Carbonate to Porous Vaterite Microparticles with Morphology Control. Cryst. Growth Des. 2019, 19 (9), 5075-5087. https://doi.org/10.1021/acs.cgd.9b00438.

(62) Schweikle, M.; Bjørnøy, S. H.; van Helvoort, A. T. J.; Haugen, H. J.; Sikorski, P.; Tiainen, H. Stabilisation of Amorphous Calcium Phosphate in Polyethylene Glycol Hydrogels. Acta Biomater. 2019, 90, 132-145. https://doi.org/10.1016/j.actbio.2019.03.044.

(63) Cantaert, B.; Kuo, D.; Matsumura, S.; Nishimura, T.; Sakamoto, T.; Kato, T. Use of Amorphous Calcium Carbonate for the Design of New Materials. ChemPlusChem 2017, 82 (1), 107-120. https://doi.org/10.1002/cplu.201600457.

(64) Yu, Y.; He, Y.; Mu, Z.; Zhao, Y.; Kong, K.; Liu, Z.; Tang, R. Biomimetic Mineralized Organic-Inorganic Hybrid Macrofiber with Spider Silk-Like Supertoughness. Adv.

Funct. Mater. 2020, 30 (6), 1908556. https://doi.org/10.1002/adfm.201908556.

(65) Weiner, S.; Levi-Kalisman, Y.; Raz, S.; Addadi, L. Biologically Formed Amorphous Calcium Carbonate. Connect. Tissue Res. 2003, 44 Suppl 1, 214-218.

(66) Shapiro, O. H.; Kartvelishvily, E.; Kramarsky-Winter, E.; Vardi, A. Magnesium-Rich Nanometric Layer in the Skeleton of Pocillopora Damicornis With Possible Involvement in Fibrous Aragonite Deposition. Front. Mar. Sci. 2018, 5, 246. https://doi.org/10.3389/fmars.2018.00246.

(67) Nebel, H.; Neumann, M.; Mayer, C.; Epple, M. On the Structure of Amorphous Calcium Carbonate - A Detailed Study by Solid-State NMR Spectroscopy. Inorg. Chem. 2008, 47 (17), 7874-7879. https://doi.org/10.1021/ic8007409.

(68) Gebauer, D.; Gunawidjaja, P. N.; Ko, J. Y. P.; Bacsik, Z.; Aziz, B.; Liu, L.; Hu, Y.; Bergström, L.; Tai, C.-W.; Sham, T.-K.; Edén, M.; Hedin, N. Proto-Calcite and ProtoVaterite in Amorphous Calcium Carbonates. Angew. Chem. Int. Ed. 2010, 49 (47), 8889-8891. https://doi.org/10.1002/anie.201003220.

(69) Michel, F. M.; MacDonald, J.; Feng, J.; Phillips, B. L.; Ehm, L.; Tarabrella, C.; Parise, J. B.; Reeder, R. J. Structural Characteristics of Synthetic Amorphous Calcium Carbonate. Chem. Mater. 2008, 20 (14), 4720-4728. https://doi.org/10.1021/cm800324v.

(70) Yang, S.-Y.; Chang, H.-H.; Lin, C.-J.; Huang, S.-J.; Chan, J. C. C. Is Mg-Stabilized Amorphous Calcium Carbonate a Homogeneous Mixture of Amorphous Magnesium 
Carbonate and Amorphous Calcium Carbonate? Chem. Commun. 2016, 52 (77), 11527-11530. https://doi.org/10.1039/C6CC04522G.

(71) Leukel, S.; Mondeshki, M.; Tremel, W. Hydrogen Bonding in Amorphous Alkaline Earth Carbonates. Inorg. Chem. 2018, 57 (17), 11289-11298. https://doi.org/10.1021/acs.inorgchem.8b02170.

(72) Von Euw, S.; Wang, Y.; Laurent, G.; Drouet, C.; Babonneau, F.; Nassif, N.; Azaïs, T. Bone Mineral: New Insights into Its Chemical Composition. Sci. Rep. 2019, 9 (1). https://doi.org/10.1038/s41598-019-44620-6.

(73) Sideris, P. J.; Nielsen, U. G.; Gan, Z.; Grey, C. P. Mg/Al Ordering in Layered Double Hydroxides Revealed by Multinuclear NMR Spectroscopy. Science 2008, 321 (5885), 113-117. https://doi.org/10.1126/science.1157581.

(74) Gaffey, S. J. $\mathrm{H}_{2} \mathrm{O}$ and $\mathrm{OH}$ in Echinoid Calcite; a Spectroscopic Study. Am. Mineral. 1995, 80 (9-10), 947-959. https://doi.org/10.2138/am-1995-9-1011.

(75) Pourpoint, F.; Gervais, C.; Bonhomme-Coury, L.; Azaïs, T.; Coelho, C.; Mauri, F.; Alonso, B.; Babonneau, F.; Bonhomme, C. Calcium Phosphates and Hydroxyapatite: Solid-State NMR Experiments and First-Principles Calculations. Appl. Magn. Reson. 2007, 32 (4), 435-457. https://doi.org/10.1007/s00723-007-0040-1.

(76) Bird, M. I.; Chivas, A. R.; Radnell, C. J.; Burton, H. R. Sedimentological and StableIsotope Evolution of Lakes in the Vestfold Hills, Antarctica. Palaeogeogr.

Palaeoclimatol. Palaeoecol. 1991, 84 (1-4), 109-130. https://doi.org/10.1016/00310182(91)90039-T.

(77) Onac, B. P. Mineralogical Studies and Uranium-Series Dating of Speleothems from Scarisoara Glacier Cave (Bihor Mountains, Romania). Theor. Appl. Karstology 2001, 13-14, 33-38.

(78) Carlström, D. A CRYSTALLOGRAPHIC STUDY OF VERTEBRATE OTOLITHS. Biol. Bull. 1963, 125 (3), 441-463. https://doi.org/10.2307/1539358.

(79) Señorale-Pose, M.; Chalar, C.; Dauphin, Y.; Massard, P.; Pradel, P.; Marín, M. Monohydrocalcite in Calcareous Corpuscles of Mesocestoides Corti. Exp. Parasitol. 2008, 118 (1), 54-58. https://doi.org/10.1016/j.exppara.2007.06.011.

(80) Catherine, H.; Skinner, W.; Osbaldiston, G. W.; Wilner, A. N. Monohydrocalcite in a Guinea Pig Bladder Stone, a Novel Occurrence. Am. Mineral. 1977, 62 (3-4), 273-277.

(81) Rodriguez-Blanco, J. D.; Shaw, S.; Bots, P.; Roncal-Herrero, T.; Benning, L. G. The Role of $\mathrm{Mg}$ in the Crystallization of Monohydrocalcite. Geochim. Cosmochim. Acta 2014, 127, 204-220. https://doi.org/10.1016/j.gca.2013.11.034.

(82) Konrad, F.; Purgstaller, B.; Gallien, F.; Mavromatis, V.; Gane, P.; Dietzel, M. Influence of Aqueous Mg Concentration on the Transformation of Amorphous Calcium Carbonate. J. Cryst. Growth 2018, 498, 381-390. https://doi.org/10.1016/j.jcrysgro.2018.07.018.

(83) Loste, E.; Wilson, R. M.; Seshadri, R.; Meldrum, F. C. The Role of Magnesium in Stabilising Amorphous Calcium Carbonate and Controlling Calcite Morphologies. $J$. Cryst. Growth 2003, 254 (1-2), 206-218. https://doi.org/10.1016/S00220248(03)01153-9.

(84) Huang, Y.-C.; Gindele, M. B.; Knaus, J.; Rao, A.; Gebauer, D. On Mechanisms of Mesocrystal Formation: Magnesium Ions and Water Environments Regulate the Crystallization of Amorphous Minerals. CrystEngComm 2018, 20 (31), 4395-4405. https://doi.org/10.1039/C8CE00241J.

(85) Nishiyama, R.; Munemoto, T.; Fukushi, K. Formation Condition of Monohydrocalcite from $\mathrm{CaCl} 2-\mathrm{MgCl} 2-\mathrm{Na} 2 \mathrm{CO} 3$ Solutions. Geochim. Cosmochim. Acta 2013, 100, $217-$ 231. https://doi.org/10.1016/j.gca.2012.09.002. 
(86) Wang, Y.-Y.; Yao, Q.-Z.; Zhou, G.-T.; Fu, S.-Q. Transformation of Amorphous Calcium Carbonate into Monohydrocalcite in Aqueous Solution: A Biomimetic Mineralization Study. Eur. J. Mineral. 2015, 27 (6), 717-729. https://doi.org/10.1127/ejm/2015/0027-2486.

(87) Kimura, T.; Koga, N. Monohydrocalcite in Comparison with Hydrated Amorphous Calcium Carbonate: Precipitation Condition and Thermal Behavior. Cryst. Growth Des. 2011, 11 (9), 3877-3884. https://doi.org/10.1021/cg200412h.

(88) Giuffre, A. J.; Gagnon, A. C.; De Yoreo, J. J.; Dove, P. M. Isotopic Tracer Evidence for the Amorphous Calcium Carbonate to Calcite Transformation by DissolutionReprecipitation. Geochim. Cosmochim. Acta 2015, 165, 407-417. https://doi.org/10.1016/j.gca.2015.06.002.

(89) Liu, Z.; Zhang, Z.; Wang, Z.; Jin, B.; Li, D.; Tao, J.; Tang, R.; De Yoreo, J. J. ShapePreserving Amorphous-to-Crystalline Transformation of $\mathrm{CaCO}_{3}$ Revealed by in Situ TEM. Proc. Natl. Acad. Sci. 2020, 117 (7), 3397-3404. https://doi.org/10.1073/pnas.1914813117.

(90) Bots, P.; Benning, L. G.; Rodriguez-Blanco, J.-D.; Roncal-Herrero, T.; Shaw, S. Mechanistic Insights into the Crystallization of Amorphous Calcium Carbonate (ACC). Cryst. Growth Des. 2012, 12 (7), 3806-3814. https://doi.org/10.1021/cg300676b.

(91) Rodriguez-Blanco, J. D.; Shaw, S.; Benning, L. G. The Kinetics and Mechanisms of Amorphous Calcium Carbonate (ACC) Crystallization to Calcite, via Vaterite. Nanoscale 2011, 3 (1), 265-271. https://doi.org/10.1039/C0NR00589D.

(92) Rodriguez-Blanco, J. D.; Shaw, S.; Bots, P.; Roncal-Herrero, T.; Benning, L. G. The Role of $\mathrm{PH}$ and $\mathrm{Mg}$ on the Stability and Crystallization of Amorphous Calcium Carbonate. J. Alloys Compd. 2012, 536, S477-S479. https://doi.org/10.1016/j.jallcom.2011.11.057.

(93) Albéric, M.; Bertinetti, L.; Zou, Z.; Fratzl, P.; Habraken, W.; Politi, Y. The Crystallization of Amorphous Calcium Carbonate Is Kinetically Governed by Ion Impurities and Water. Adv. Sci. 2018, 5 (5), 1701000. https://doi.org/10.1002/advs.201701000.

(94) Du, H.; Steinacher, M.; Borca, C.; Huthwelker, T.; Murello, A.; Stellacci, F.; Amstad, E. Amorphous $\mathrm{CaCO}_{3}$ : Influence of the Formation Time on Its Degree of Hydration and Stability. J. Am. Chem. Soc. 2018, 140 (43), 14289-14299. https://doi.org/10.1021/jacs.8b08298.

(95) Wang, Y.; Von Euw, S.; Fernandes, F. M.; Cassaignon, S.; Selmane, M.; Laurent, G.; Pehau-Arnaudet, G.; Coelho, C.; Bonhomme-Coury, L.; Giraud-Guille, M.-M.; Babonneau, F.; Azaïs, T.; Nassif, N. Water-Mediated Structuring of Bone Apatite. Nat. Mater. 2013, 12 (12), 1144-1153. https://doi.org/10.1038/nmat3787.

(96) Neumann, M.; Epple, M. Monohydrocalcite and Its Relationship to Hydrated Amorphous Calcium Carbonate in Biominerals. Eur. J. Inorg. Chem. 2007, 2007 (14), 1953-1957. https://doi.org/10.1002/ejic.200601033.

(97) Dauphin, Y. Nanostructures of the nacreous layers in Recent cephalopod shells. Paläontol. Z. 2001, 75 (1), 113-122. https://doi.org/10.1007/BF03022601.

(98) Gilbert, P. U. P. A.; Porter, S. M.; Sun, C.-Y.; Xiao, S.; Gibson, B. M.; Shenkar, N.; Knoll, A. H. Biomineralization by Particle Attachment in Early Animals. Proc. Natl. Acad. Sci. 2019, 116 (36), 17659-17665. https://doi.org/10.1073/pnas.1902273116.

(99) Gal, A.; Kahil, K.; Vidavsky, N.; DeVol, R. T.; Gilbert, P. U. P. A.; Fratzl, P.; Weiner, S.; Addadi, L. Particle Accretion Mechanism Underlies Biological Crystal Growth from an Amorphous Precursor Phase. Adv. Funct. Mater. 2014, 24 (34), 5420-5426. https://doi.org/10.1002/adfm.201400676. 
(100) Gal, A.; Weiner, S.; Addadi, L. A Perspective on Underlying Crystal Growth Mechanisms in Biomineralization: Solution Mediated Growth versus Nanosphere Particle Accretion. CrystEngComm 2015, 17 (13), 2606-2615. https://doi.org/10.1039/C4CE01474J.

(101) De Yoreo, J. J.; Gilbert, P. U. P. A.; Sommerdijk, N. A. J. M.; Penn, R. L.; Whitelam, S.; Joester, D.; Zhang, H.; Rimer, J. D.; Navrotsky, A.; Banfield, J. F.; Wallace, A. F.; Michel, F. M.; Meldrum, F. C.; Colfen, H.; Dove, P. M. Crystallization by Particle Attachment in Synthetic, Biogenic, and Geologic Environments. Science 2015, 349 (6247), aaa6760-aaa6760. https://doi.org/10.1126/science.aaa6760.

(102) Walker, J. M.; Marzec, B.; Nudelman, F. Solid-State Transformation of Amorphous Calcium Carbonate to Aragonite Captured by CryoTEM. Angew. Chem. 2017, 129 (39), 11902-11905. https://doi.org/10.1002/ange.201703158.

(103) Lin, C.-J.; Yang, S.-Y.; Huang, S.-J.; Chan, J. C. C. Structural Characterization of MgStabilized Amorphous Calcium Carbonate by Mg-25 Solid-State NMR Spectroscopy. J. Phys. Chem. C 2015, 119 (13), 7225-7233. https://doi.org/10.1021/jp512971a.

(104) Dorvee, J. R.; Veis, A. Water in the Formation of Biogenic Minerals: Peeling Away the Hydration Layers. J. Struct. Biol. 2013, 183 (2), 278-303. https://doi.org/10.1016/j.jsb.2013.06.007.

(105) Sen, S.; Kaseman, D. C.; Colas, B.; Jacob, D. E.; Clark, S. M. Hydrogen Bonding Induced Distortion of $\mathrm{CO}_{3}$ Units and Kinetic Stabilization of Amorphous Calcium Carbonate: Results from 2D ${ }^{13}$ C NMR Spectroscopy. Phys. Chem. Chem. Phys. 2016, 18 (30), 20330-20337. https://doi.org/10.1039/C6CP02729F.

(106) Rodriguez-Navarro, C.; Burgos Cara, A.; Elert, K.; Putnis, C. V.; Ruiz-Agudo, E. Direct Nanoscale Imaging Reveals the Growth of Calcite Crystals via Amorphous Nanoparticles. Cryst. Growth Des. 2016, 16 (4), 1850-1860. https://doi.org/10.1021/acs.cgd.5b01180.

(107) Kababya, S.; Gal, A.; Kahil, K.; Weiner, S.; Addadi, L.; Schmidt, A. Phosphate-Water Interplay Tunes Amorphous Calcium Carbonate Metastability: Spontaneous Phase Separation and Crystallization vs Stabilization Viewed by Solid State NMR. J. Am. Chem. Soc. 2015, 137 (2), 990-998. https://doi.org/10.1021/ja511869g.

(108) Drake, J.; Mass, T.; Stołarski, J.; Von Euw, S.; van de Schootbrugge, B.; Falkowski, P. G. How Corals Made Rocks through the Ages. Glob. Change Biol. 2019, gcb.14912. https://doi.org/10.1111/gcb.14912.

(109) Sun, C.-Y.; Marcus, M. A.; Frazier, M. J.; Giuffre, A. J.; Mass, T.; Gilbert, P. U. P. A. Spherulitic Growth of Coral Skeletons and Synthetic Aragonite: Nature's ThreeDimensional Printing. ACS Nano 2017, 11 (7), 6612-6622. https://doi.org/10.1021/acsnano.7b00127. 

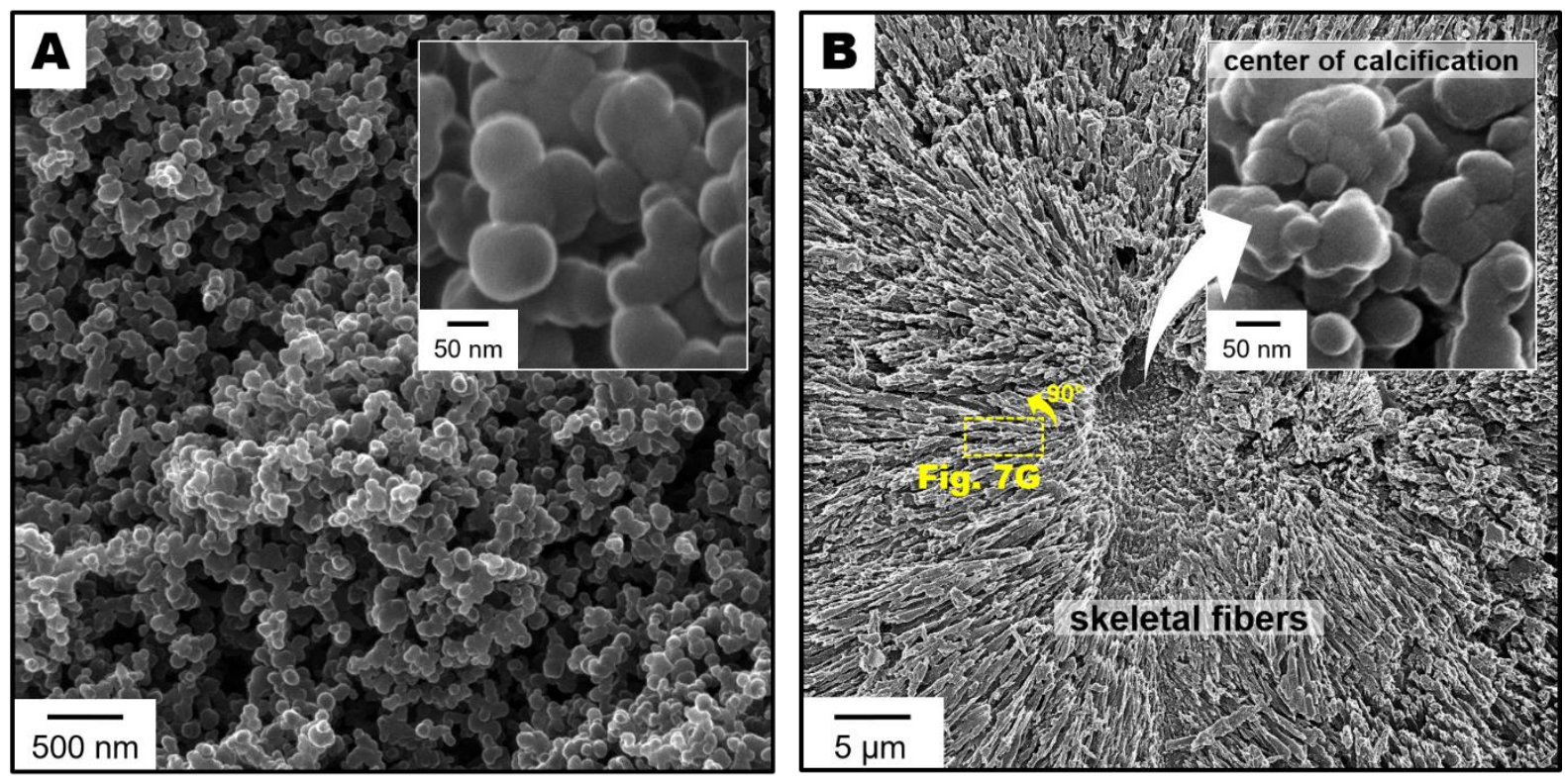

Figure 1. Morphological features of synthetic and biogenic amorphous nanoparticles.

909 Representative scanning helium ion microscopy (SHIM) micrographs of the synthetic,

910 Amorphous Calcium Magnesium Carbonate (ACMC) sample (A). For the purpose of

911 comparison with biogenic deposits of amorphous $\mathrm{CaCO}_{3}$, also shown are representative

912 SHIM micrographs obtained from the broken, unpolished, etched-surface of a coral skeletal

913 branch that was transversely sectioned (B). Shown here is a trabecula composed of skeletal

914 fibers in the form of acicular aragonite crystals, that radiate from a center of calcification

915 (COC) composed of magnesium-rich, amorphous calcium carbonate nanoparticles ${ }^{108}$. 

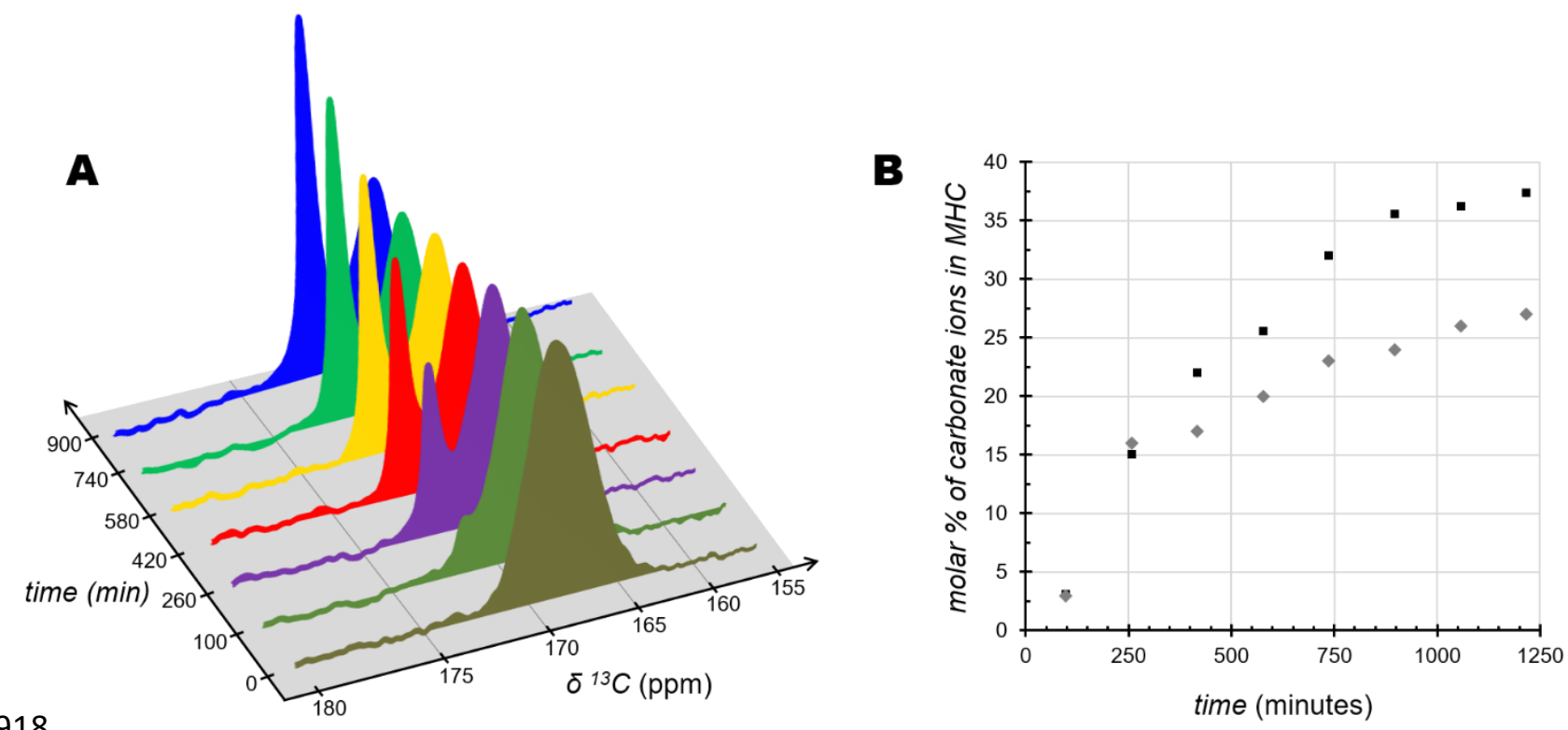

Figure 2. Kinetics of crystallization of the synthetic amorphous nanoparticles. (A) Non-

920 normalized $1 D^{13} \mathrm{C}$ single-pulse (SP) MAS ssNMR spectra (recycling delay, RD = $600 \mathrm{~s}$;

921 number of scans, NS $=8$; MAS frequency, $v_{\text {MAS }}=8 \mathrm{kHz}$ ) of the synthetic, Amorphous

922 Calcium Magnesium Carbonate (ACMC) sample soaked in deionized water as crystallization

923 progresses. (B) Conversion rate of the starting amorphous environments into

924 monohydrocalcite as a function of time for ACMC soaked in deionized water (black squares)

925 or heavy water (grey squares). This conversion rate is here expressed in terms of the molar

926 percentage of carbonate ions present in monohydrocalcite (MHC) environments. 
Figure 3.
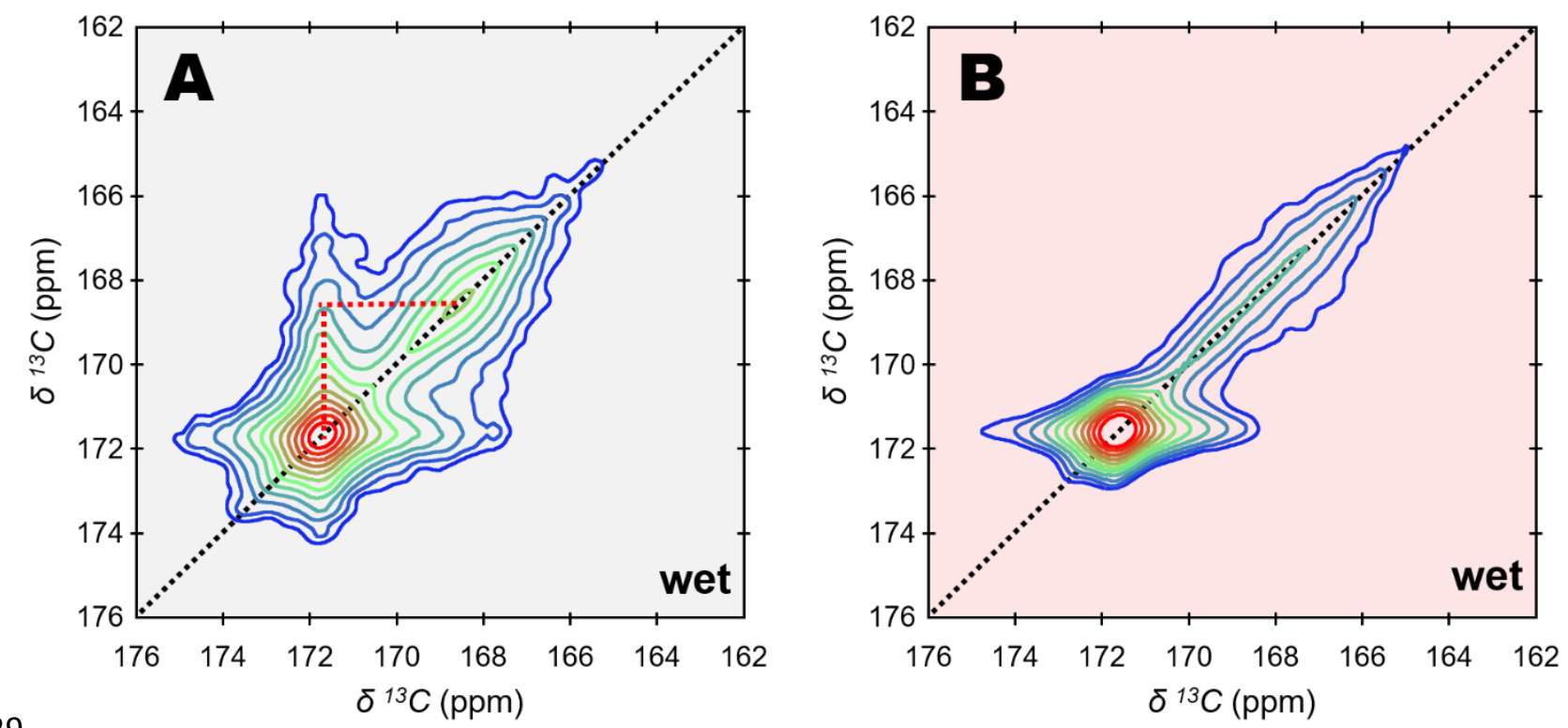

930 Figure 3. Spatial proximities among the carbon-bearing ions. Contour plots of two-

931 dimensional (2D) ${ }^{13} \mathrm{C}-{ }^{13} \mathrm{C}$ Dipolar Assisted Rotational Resonance (DARR) MAS ssNMR

932 spectra (contact time, $\mathrm{t}_{\mathrm{CP}}=4 \mathrm{~ms}$; mixing time, $\tau_{\mathrm{mix}}=500 \mathrm{~ms} ; 8$ scans in each $384 \mathrm{t} 1$

933 increments; relaxation delay, RD $=1 \mathrm{~s}$; MAS frequency, $v_{\mathrm{MAS}}=8 \mathrm{kHz}$ ) of the synthetic,

934 Amorphous Calcium Magnesium Carbonate (ACMC) sample soaked in deionized water, and

935 partially converted into monohydrocalcite (conversion rate, 30\%) (A); and of a physical

936 mixture of two powders soaking in deionized water: the synthetic monohydrocalcite (MHC)

937 sample and ACMC before crystallization (B). The signal intensity increases from blue to red. 
939

940

941

942

943
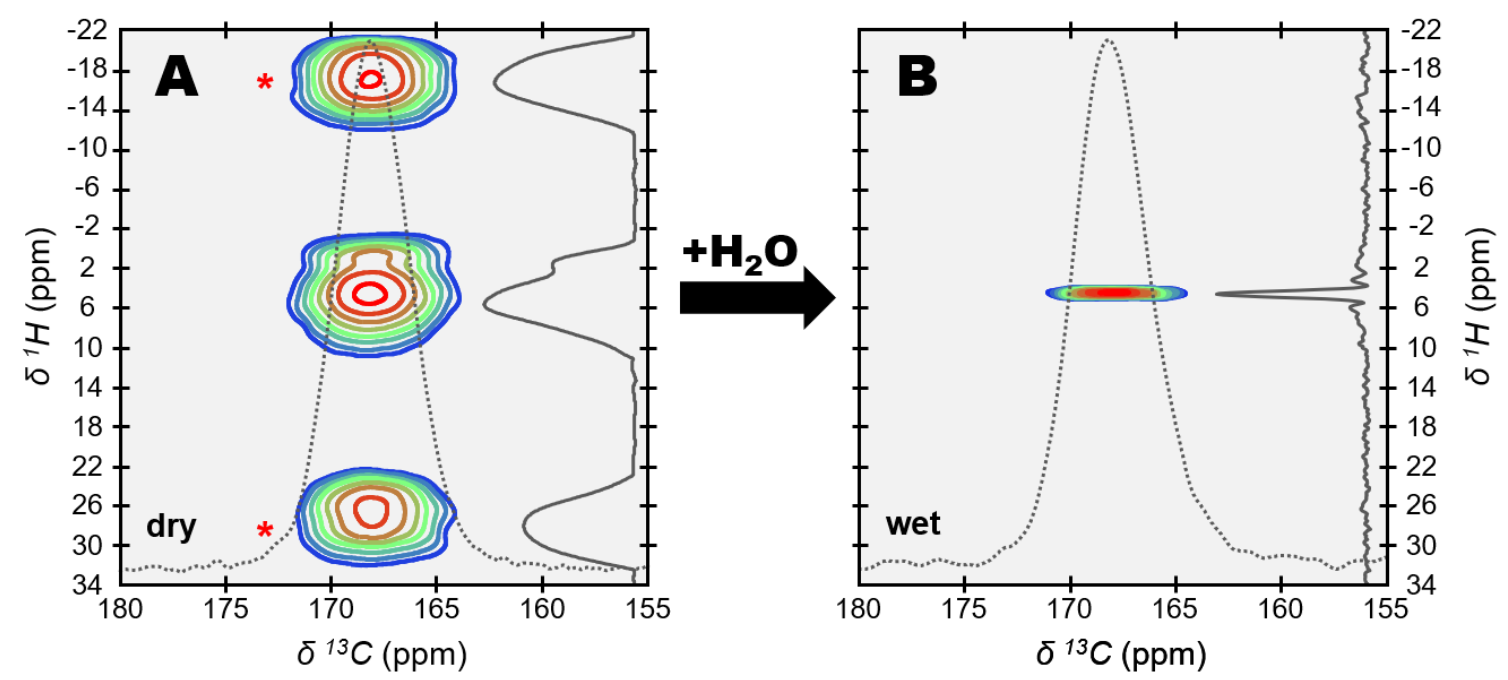

\section{Figure 4. Spatial proximities among carbon-bearing ions and hydrogen-bearing}

ions/molecules in the amorphous nanoparticles. Contour plots of two-dimensional (2D)

$\left\{{ }^{1} \mathrm{H}\right\}{ }^{13} \mathrm{C}$ Heteronuclear Correlation (HetCor) MAS ssNMR spectra [contact time, $\mathrm{t}_{\mathrm{CP}}=4 \mathrm{~ms}$;

64 (dry conditions) or 16 (wet conditions) scans in each 120 t1 increments; relaxation delay, $\mathrm{RD}=2 \mathrm{~s} ;$ MAS frequency, $\left.v_{\mathrm{MAS}}=8 \mathrm{kHz}\right]$ of the synthetic, Amorphous Calcium Magnesium Carbonate (ACMC) sample in dry conditions (A) and soaked in deionized water for 50 minutes (B). The signal intensity increases from blue to red. Also shown are the normalized, projections of the vertical, indirect ${ }^{1} \mathrm{H}$ dimensions (solid lines) and of the horizontal, direct ${ }^{13} \mathrm{C}$ dimensions (dotted lines) of these two $2 \mathrm{D}\left\{{ }^{1} \mathrm{H}\right\}{ }^{13} \mathrm{C}$ HetCor MAS ssNMR spectra. The red asterisks $(*)$ denote the intense spinning sidebands only seen in dry conditions. 

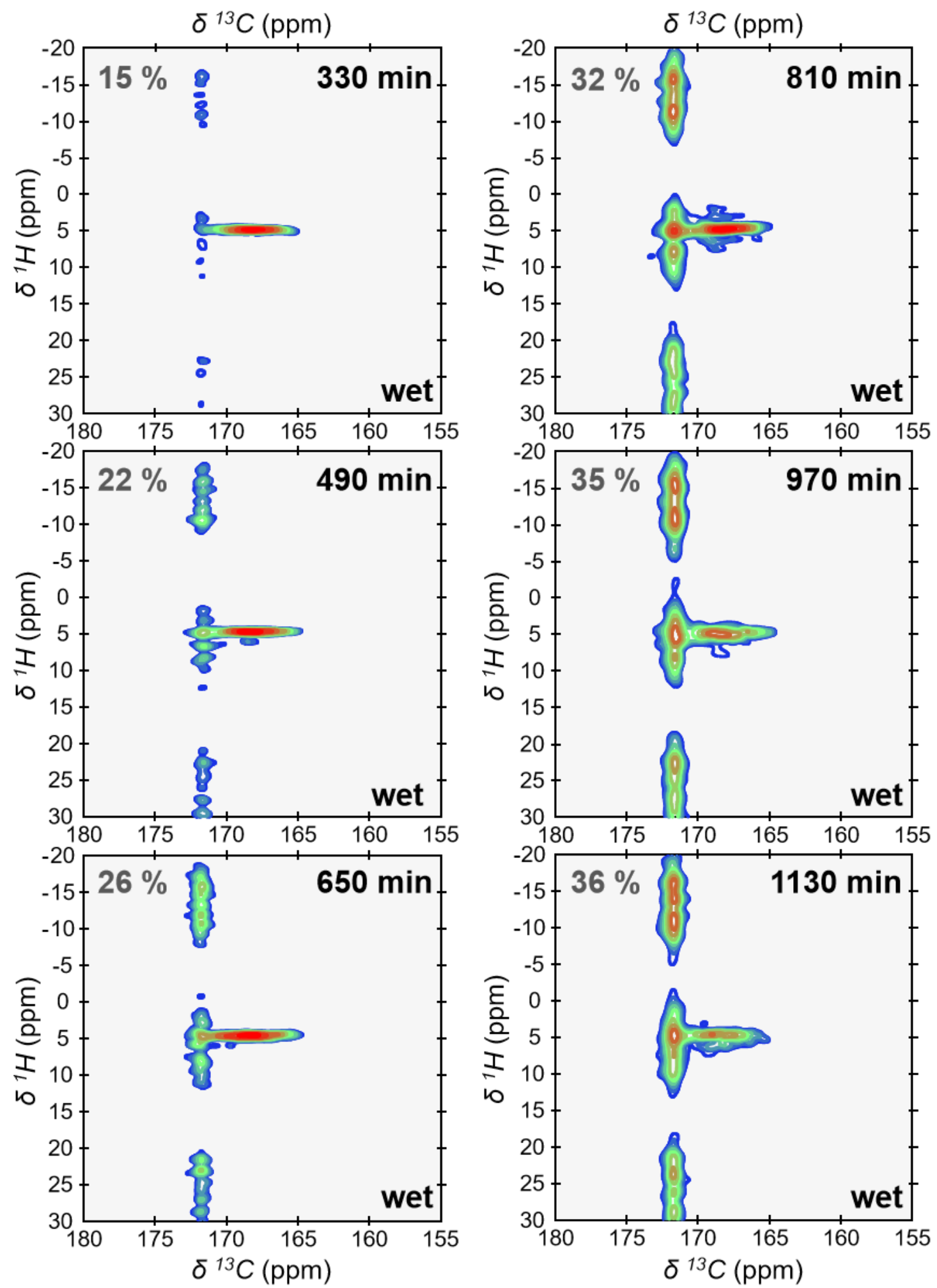

952 Figure 5. Evolution of the hydrogen chemical environments during crystallization.

953 Contour plots of 2D $\left\{{ }^{1} \mathrm{H}\right\}{ }^{13} \mathrm{C}$ Heteronuclear Correlation (HetCor) MAS ssNMR spectra 
954 (contact time, $\mathrm{t}_{\mathrm{CP}}=4 \mathrm{~ms} ; 16$ scans in each $120 \mathrm{t} 1$ increments; relaxation delay, $\mathrm{RD}=2 \mathrm{~s}$;

955 MAS frequency, $v_{\text {MAS }}=8 \mathrm{kHz}$ ) of the synthetic, Amorphous Calcium Magnesium Carbonate 956 (ACMC) sample soaked in deionized water while crystallization progresses. The signal 957 intensity increases from blue to red. The percentages displayed in the upper left corner are the 958 conversion rate of ACMC into monohydrocalcite, whereas the values shown in the upper right 959 corner are the periods of time during which the sample has been soaking in water following 960 the initial wetting step. 

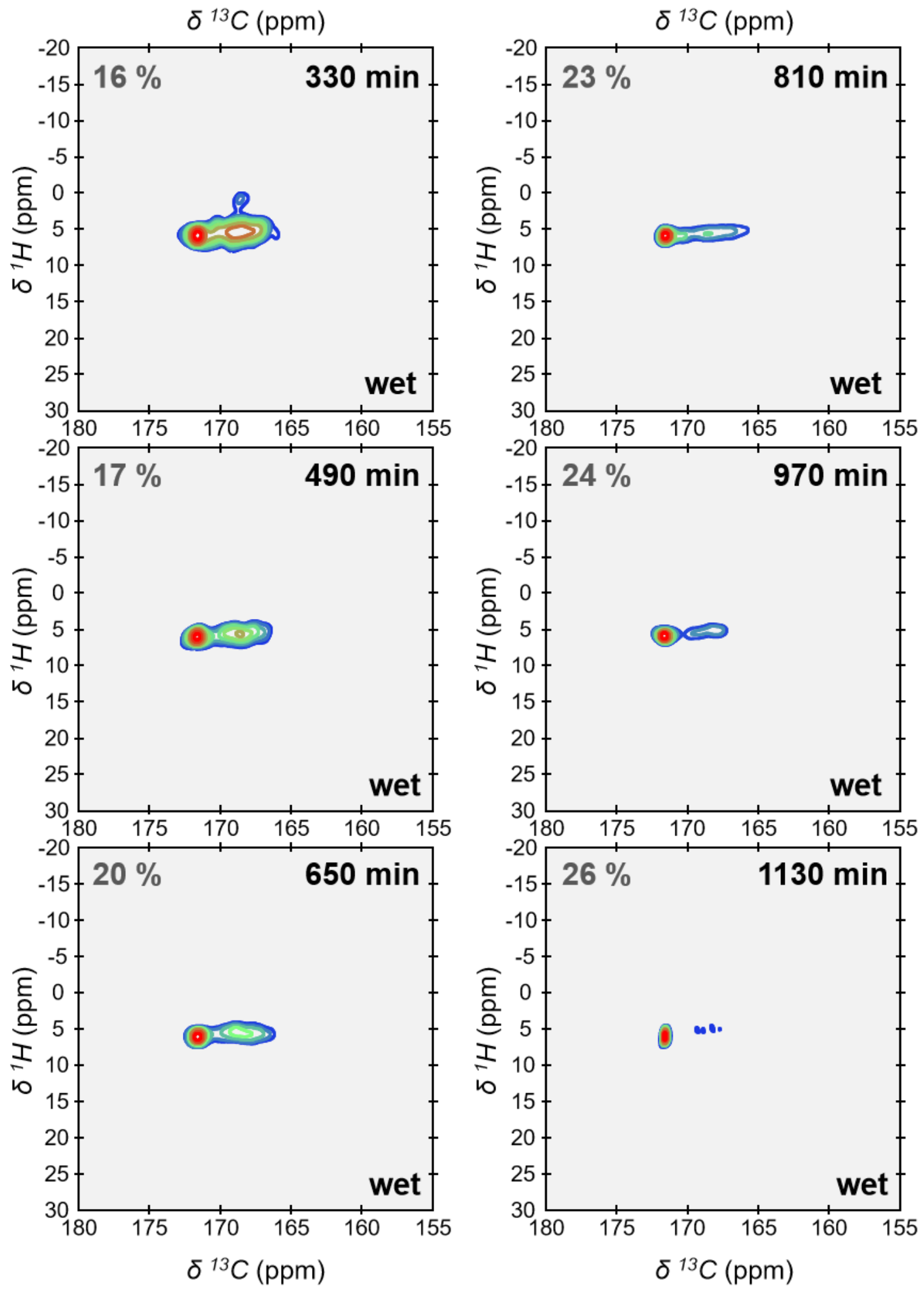

963 Figure 6. Deuterium-hydrogen chemical exchanges during crystallization. Contour plots 964 of $2 \mathrm{D}\left\{{ }^{1} \mathrm{H}\right\}{ }^{13} \mathrm{C}$ Heteronuclear Correlation (HetCor) MAS ssNMR spectra (contact time, $\mathrm{t}_{\mathrm{CP}}=$ 
$9654 \mathrm{~ms} ; 16$ scans in each $120 \mathrm{t} 1$ increments; relaxation delay, RD = $2 \mathrm{~s} ;$ MAS frequency, $v_{\mathrm{MAS}}=$ $9668 \mathrm{kHz}$ ) of the synthetic, Amorphous Calcium Magnesium Carbonate (ACMC) sample soaked 967 in heavy water $\left(\mathrm{D}_{2} \mathrm{O}-99.99\right.$ atom\% $\left.\mathrm{D}\right)$ while crystallization progresses. The signal intensity 968 increases from blue to red. The percentages displayed in the upper left corner are the 969 conversion rate of ACMC into monohydrocalcite, whereas the values shown in the upper right 970 corner are the periods of time during which the sample has been soaking in heavy water 971 following the initial wetting step. 

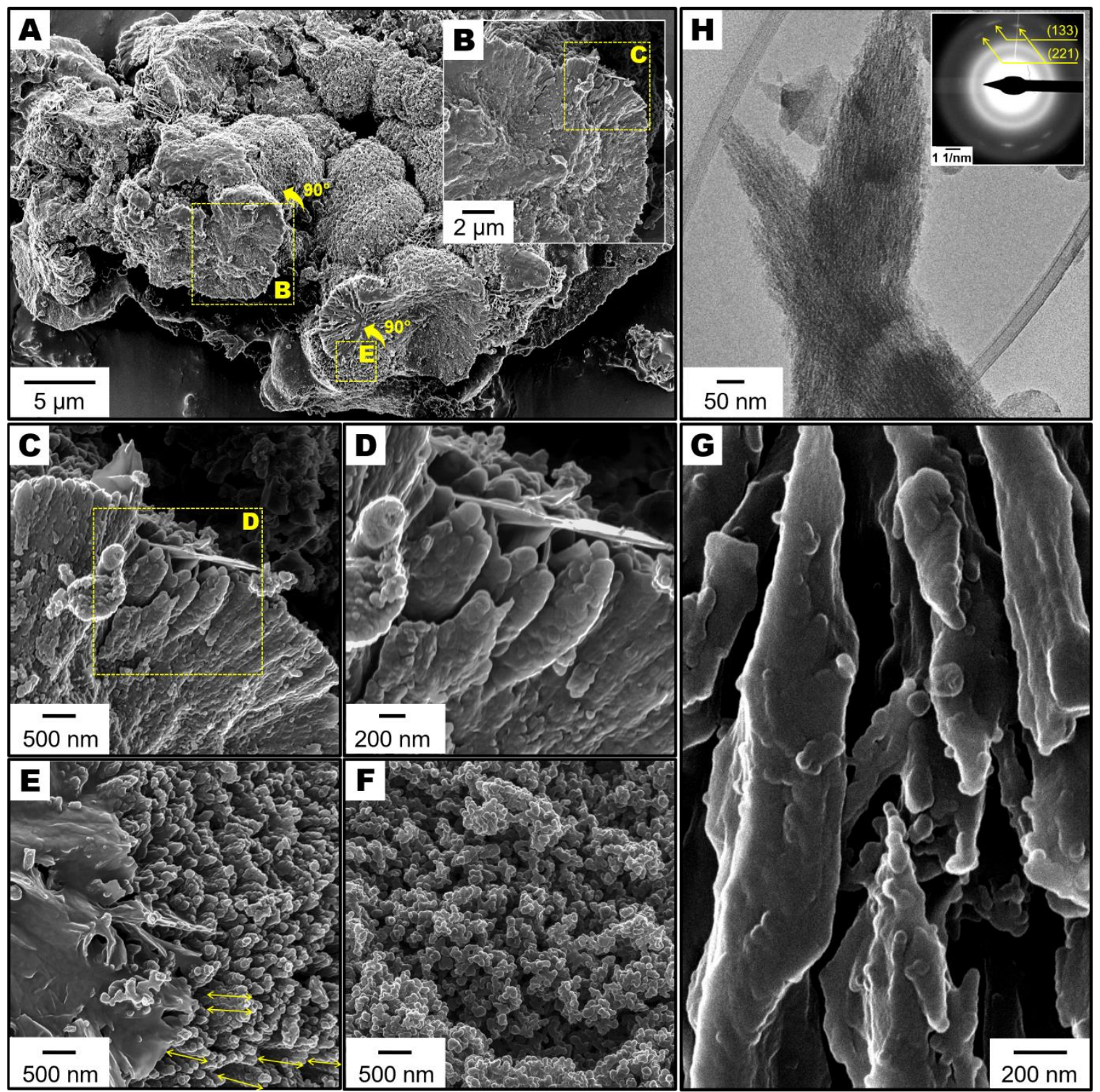

$974 \quad$ Figure 7. Higher-order mineral structures following crystallization. Representative

975 scanning helium ion microscopy (SHIM) micrographs of the higher-order mineral structures

976 resulting from the crystallization of the synthetic, Amorphous Calcium Magnesium Carbonate

977 (ACMC) sample soaked in deionized water in the MAS rotor (A to $\mathbf{E}$ ); and of the ACMC

978 nanoparticles shown before crystallization $(\mathbf{F})$. (A) is a low magnification micrograph that

979 displays the presence of spherulitic aggregates. (B to D) and (E) are different micrographs at

980 higher magnifications that reveal the features of the monohydrocalcite crystals that compose 
981 the spherulitic aggregates shown in (A). For the purpose of comparison with biogenic crystals

982 observed in coral skeleton, $(\mathbf{G})$ shows a magnification of the square region marked by the

983 yellow dashed line drawn in Fig. 1B. This high magnification micrograph exposes the skeletal

984 fibers of a trabecula formed via a spherulitic growth mechanism ${ }^{109}$, and shows the "nano-

985 particulate" texture of the acicular aragonite crystals. (H) Representative cryogenic

986 transmission electron microscopy (cryo-TEM) micrograph of the higher-order mineral

987 structures resulting from the crystallization of the synthetic ACMC sample soaked in

988 deionized water in a $10 \mathrm{ml}$ vial. Inset shows a selected area electron diffraction (SAED)

989 pattern of $(\mathrm{H})$ labeled with monohydrocalcite crystal planes. 


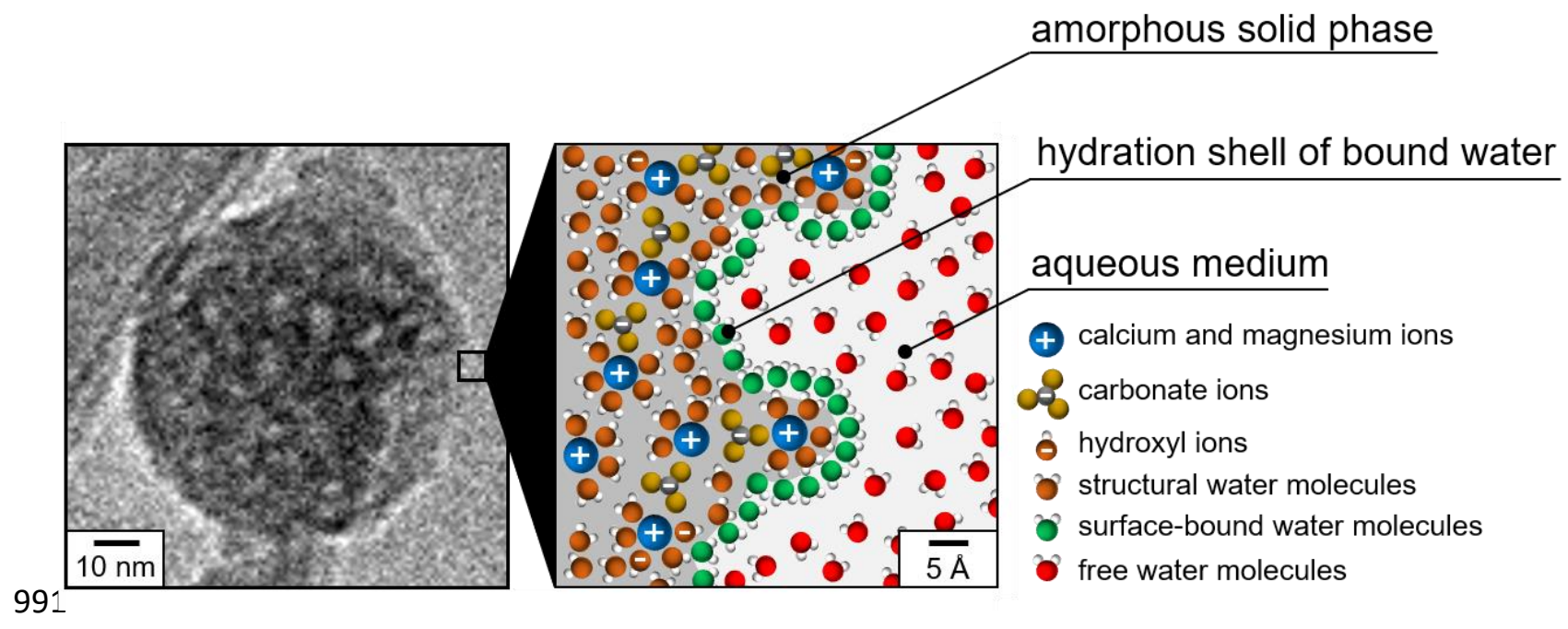

992 Figure 8. Chemical and structural model of the synthetic amorphous nanoparticles.

993 Representative cryogenic transmission electron microscopy (cryo-TEM) micrograph of a

994 nanoparticle (diameter, about $80 \mathrm{~nm}$ ) of the synthetic, Amorphous Calcium Magnesium

995 Carbonate (ACMC) sample dispersed in deionized water (left). Also shown is a two-

996 dimensional chemical and structural model of the surface region of an amorphous particle of

997 ACMC soaked in water (right). 


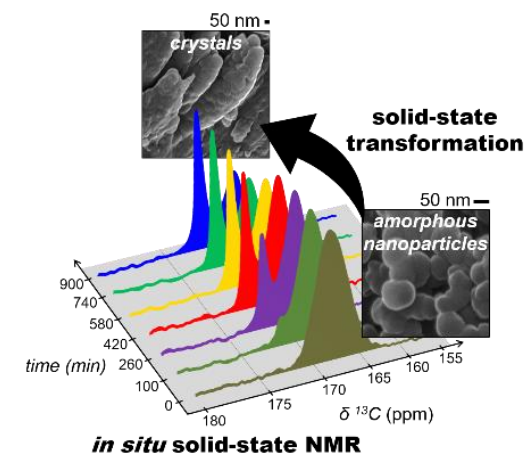

Table of Contents (TOC) image 